\section{Valence and metal/silicate partitioning of Mo: Implications for conditions of Earth} accretion and core formation

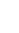

(1)

5

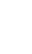

(1)

8

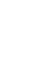

0

1

$2{ }^{1}$ Mailcode XI2, NASA Johnson Space Center, Houston, TX 77058; kevin.righter-1 @ nasa.gov

3
\footnotetext{
(corresponding author)

2 JETS, NASA Johnson Space Center, Houston, TX 77058
}

${ }^{3}$ Department of Physics, Astronomy and Geosciences, Towson University, Smith Hall, Towson,

${ }^{4}$ Center for Advanced Radiation Sources, 5640 S. Ellis, Univ. of Chicago, Chicago, IL 60637
${ }^{5}$ Dept. of the Geophysical Sciences, 5734 S. Ellis, Univ. of Chicago, Chicago, IL 60637
${ }^{6}$ Department of Earth Sciences, MS-126, Rice University, Houston, TX 77005


22 Abstract - To better understand and predict the partition coefficient of Mo at the conditions of 23 the deep interior of Earth and other terrestrial planets or bodies, we have undertaken new measurements of the valence and partitioning of Mo. X-ray absorption near edge structure (XANES) K-edge spectra for Mo have been measured in a series of Fe-bearing glasses produced at 1 bar and higher PT conditions. High pressure experiments have been carried out up to 19 GPa in order to better understand the effect of pressure on Mo partitioning. And, finally, a series of experiments at very low $\mathrm{fO}_{2}$ conditions and high $\mathrm{Si}$ content metallic liquids has been carried out to constrain the effect of $\mathrm{Si}$ on the partitioning of Mo between metallic liquids and silicate melt. The valence measurements demonstrate that Mo undergoes a transition from 4+ to 6+ near IW-1, in general agreement with previous 1 bar studies on FeO-free silicate melts. High pressure experiments demonstrate a modest pressure dependence of $\mathrm{D}(\mathrm{Mo})$ metal/silicate and, combined with previous results, show a significant decrease with pressure that must be quantified in any predictive expression. Finally, the effect of dissolved Si in Fe-rich metallic liquid is to decrease $\mathrm{D}(\mathrm{Mo})$ significantly, as suggested by previous work in metallurgical systems. The effect of pressure, temperature, oxygen fugacity, metallic liquid composition, and silicate melt composition, can be quantified by using multiple linear regression of available experimental data for Mo. Our XANES results show that Mo will be 4+ at conditions of core formation, so only experiments carried out at $\mathrm{fO}_{2}$ of IW-1 and lower were used in the regressions. Application of predictive expressions to Earth accretion shows that D(Mo) decreases to values consistent with an equilibrium scenario for early Earth core-mantle. The Mo

42 content of the primitive upper mantle (PUM) can be attained by metal-silicate equilibrium 43 involving S-, C-, and Si-bearing metallic liquid, and peridotite silicate melt along the peridotite 44 liquidus near $45 \mathrm{GPa}$ and $3600{ }^{\circ} \mathrm{C}$, late in the accretion process. This conclusion is insensitive to 45 late giant impacts unless the degree of equilibration is very low $(<5 \%)$. 


\section{Introduction}

Siderophile elements have an affinity for Fe-rich metallic liquids and thus offer

49 information about the conditions of core formation in terrestrial planets. The distribution of

50 siderophile elements (e.g., Fe, Ni, Co, Mo, W) between metal and silicate melt depends upon the

51 variables of pressure, temperature, silicate melt and metal composition, and oxygen fugacity. As

52 such, an understanding of their partitioning behavior can lead to a better understanding of the

53 conditions surrounding the formation of the metallic core of the Earth and other differentiated

54 planetary bodies for which we have samples of their mantles or basaltic crusts.

Molybdenum is an important siderophile element for several reasons: a) it is refractory

56 which means its abundances in the Earth's mantle and building blocks are better known than

57 most elements $-23 \pm 7$ ppb (Greber et al., 2015), b) it is a moderately siderophile element which

58 means its partition coefficient between the core and mantle is a large number, possibly between

5910 and 1000, nonetheless leaving a significant concentration in the mantle, c) it has a well-

60 defined depletion in the Earth's primitive upper mantle compared to chondrites, and d) it carries

61 important isotopic anomalies that may result from metal-silicate partitioning and/or nebular

62 heterogeneity and thus understanding the partitioning behavior can help constrain when Mo

63 isotopic signature was established. Despite these attractions, molybdenum partitioning between

64 metal and silicate melt is more difficult to quantify in natural systems due to uncertainties in (1)

65 its valence at high temperature and pressure, (2) the effect of high pressures, and (3) the effect of

66 dissolved light elements (S, C, and $\mathrm{Si})$ in the metallic liquid.

67

First, Mo can be stable in two oxidation states $(4+$ and $6+)$ in silicate melts and the transition between $4+$ and $6+$ takes place under oxygen fugacity conditions near the IW buffer at 
1 bar (e.g., Holzheid et al., 1994; Farges et al., 2006a,b). Although various studies have tried to

70 constrain the valence (Holzheid et al., 1994; Farges et al., 2006a,b; Wade et al., 2012), the

71 approaches are either indirect with large uncertainties based on solubility or D(Mo) metal/silicate

72 (wt\% Mo in metal / wt \% Mo in silicate) variation with $\mathrm{fO}_{2}$, or they are based on measurements

73 on $\mathrm{FeO}$-free and/or $\mathrm{SiO}_{2}-\mathrm{Na}_{2} \mathrm{O}-\mathrm{Al}_{2} \mathrm{O}_{3}$ melts at temperatures of 1100 to $1400{ }^{\circ} \mathrm{C}$. Because $4+$ or

$746+$ cation solubility in a silicate melt will be strongly $\mathrm{fO}_{2}$ dependent, and solubility is linked to

75 the value of $\mathrm{D}(\mathrm{Mo})$ metal/silicate, it is very important to know under what conditions Mo is 4+

76 and/or 6+ and whether that transition occurs at $\mathrm{fO}_{2} \mathrm{~s}$ that are within the range of core formation

77 especially at the high temperature and pressure conditions at which the core may have formed.

Second, current models predict high PT metal-silicate equilibrium conditions (30 to 70

$79 \mathrm{GPa} ; 3000-4000 \mathrm{~K})$ to explain Mo content of the mantle, but most experimental data are acquired

80 from experiments at relatively low PT conditions ( $<10 \mathrm{GPa},<2300 \mathrm{~K})$, especially relative to

81 moderately siderophile elements such as Ni, Co, or W (Cottrell et al., 2009; Kegler et al., 2008).

82 Mo solubility in silicate melts is strongly dependent upon silicate melt structure and composition

83 (e.g., O’Neill and Eggins, 2002). Melt structure can change significantly at higher pressures

84 (e.g., Poe et al., 2001; Sanloup, 2013). Therefore, more partitioning data at the high pressures of

85 a deep magma ocean are needed, and a solid understanding of these effects is needed before 86 quantitative and high precision modeling can be undertaken.

Third, Earth's core contains $10 \mathrm{wt} \%$ of a light element that might include all or some of

88 C, S, Si, H, O or N (e.g., Hillgren et al., 2000). The effects of C and S are well understood 89 through various previous studies (Siebert et al., 2011; Wade et al., 2012; Jana and Walker, 90 1997a,b). Because Si has been proposed as a major component of the Earth's core (Armytage et 
91 al., 2011; Shahar et al.; 2009; Georg et al., 2007; Ziegler et al., 2010; Savage and Moynier, 2013;

92 Fitoussi et al., 2009; Chakraborti and Jacobsen, 2010; Dauphas et al., 2015), understanding the

93 magnitude of its effect is important. There is an indication that $\mathrm{D}(\mathrm{Mo})$ metal/silicate may be

94 strongly dependent upon the Si content of the Fe metallic liquid (Ono-Nakazato et al., 2007; Tuff

95 et al., 2011), but the magnitude of the effect is unclear, with Tuff et al (2011) reporting a weaker

96 effect than Ono-Nakazato et al. (2007). Additional work on the effect of Si on D(Mo)

97 metal/silicate is important in achieving confidence in the modeling calculations of Mo in the 98 primitive Earth's mantle.

In order to better understand the partitioning behavior of Mo between metal and silicate 100 melt, we have undertaken a study to a) measure the valence of Mo in experimental glasses 101 equilibrated with $\mathrm{Fe}$ metal liquid across a wide range of $\mathrm{P}-\mathrm{T}-\mathrm{fO}_{2}$ conditions using XANES 102 spectroscopy, b) isolate the effect of pressure on $\mathrm{D}(\mathrm{Mo})$ metal/silicate, and c) isolate the effect 103 of Si on $\mathrm{D}(\mathrm{Mo})$ metal/silicate. The results were combined with data from previous studies of 104 D(Mo) metal/silicate (Siebert et al., 2011; Wade et al., 2012; Tuff et al., 2011; Hillgren et al., 105 1996; Walter and Thibault, 1995; Righter et al., 1997; Jana and Walker, 1997a,b; Wade and 106 Wood, 2001; Righter and Drake, 1999; Righter et al., 2010) and then applied to core formation 107 modeling for the Earth.

108 Experiments

109

110

Partitioning experiments

111 Piston cylinder $(1 \mathrm{GPa})$ 
Metal-silicate equilibrium experiments were carried out in a piston cylinder apparatus to 113 investigate the effect of $\mathrm{Si}$ (in Fe liquid) on $\mathrm{D}(\mathrm{Mo})$ by comparison to Si-free series of Righter et 114 al. (2010) (Table S1 and S2). Experiments at $1.0 \mathrm{GPa}$ and $1600{ }^{\circ} \mathrm{C}$ were conducted using a non 115 end-loaded piston cylinder apparatus at NASA-JSC. Experimental details of pressure and 116 temperature control, and the assemblies were presented in Filiberto et al. (2008) and Righter et 117 al. (2006). The sample used in this series of experiments was composed of 70 wt\% Knippa 118 Basalt, the composition of which is described in Lewis et al. (1993), 29 wt\% Fe and 1 wt\% $119 \mathrm{MoO}_{3}$ (Table S1; Supplementary Information). Addition of Si metal to the mixture resulted in 120 variable amounts of $\mathrm{Si}$ in the metallic liquids which in turn resulted in variable $\mathrm{fO}_{2}\left(\mathrm{see} \mathrm{fO}_{2}\right.$ 121 section in "Results" below) in the sample. These mixtures were ground to a powder and 122 mechanically mixed again. Graphite capsules were used, and once samples were under pressure, 123 they were heated to silicate superliquidus temperatures, and then equilibrated at $1600{ }^{\circ} \mathrm{C}$. Run 124 durations were chosen based on equilibration times from previous experiments (Righter et al., 125 2010, Berthet et al., 2009; Table S2). The samples were then power quenched to a silicate glass 126 which contained large metallic liquid spheres (Fig. 1; cow 3 and cow B1).

127 Multi-anvil

To investigate $\mathrm{D}(\mathrm{Mo})$ at high pressure and temperature conditions, where there are fewer 129 experimental data available, we carried out several experiments in a multi-anvil apparatus, 130 between 12 and $19 \mathrm{GPa}$ (Table S2). Run charges were contained in graphite and single crystal $131 \mathrm{MgO}$ capsules (Table S2). Pressure and temperature in the multi-anvil experiments were 132 generated using COMPRES 10/5 and 8/3 assemblies, and calibrated as reported in Righter et al. 133 (2008) and Shofner et al. (2014). The samples were also power quenched to a silicate glass 
134 which contained metallic liquid spheres (Fig. 1; GN24). Some of the experimental glasses were used for XANES measurements as well as partitioning studies. The experiments of Shofner (2011) focused on $\mathrm{D}(\mathrm{W})$ metal/silicate partitioning, but Mo was added to many of the experimental runs; the metals were analyzed by EMPA (most contained $~ 0.3 \mathrm{wt} \% \mathrm{Mo}$ ) and reported in the thesis, but the silicates contained Mo concentrations $<100 \mathrm{ppm}$. We have analyzed experiments carried out at 12 to $16 \mathrm{GPa}$, where sample starting materials consisted of natural peridotite powder (DMP56 and DMP60; Rudnick et al., 2004), mixed with Fe and W metals (Table S1).

\section{Mo-bearing glass experiments for valence measurements}

To create samples with ample Mo contents to measure XANES spectra and determine valences of Mo, we synthesized some Mo-bearing glasses at 1 bar and also elevated pressure. Two compositions were studied at 1 bar and at variable $\mathrm{fO}_{2}-$ ankaramite and basalt (Table S1). The ankaramite series was doped with 500 ppm Mo, whereas the basalt series was un-doped. For the ankaramite series the powder was pressed into a pellet and hung from a Re wire basket, whereas for the basalt (Figure 1; Mo cow IW-0.5), the pellet was hung from a Re wire loop. Both of these samples were 3 to $4 \mathrm{~mm}$ in diameter, and were equilibrated at $1300{ }^{\circ} \mathrm{C}$ for 5 days $(120$ hours). Oxygen fugacity was controlled by mixtures of $\mathrm{CO}-\mathrm{CO}_{2}$ gas and varied from IW+2 to IW-2.8 (Table S2). Glasses were drop quenched into water, thus assuring a quench rate of $>500$ ${ }^{\circ} \mathrm{C} / \mathrm{s}$. The high pressure glasses were produced in the multi-anvil apparatus at 12 to $24 \mathrm{GPa}$ and 2000 to $2200{ }^{\circ} \mathrm{C}$ (Table S2). These experiments included the Knippa basalt (Table S1) doped with 100 ppm Mo contained by a graphite capsule.

\section{Previous experiments}


For valence measurements, experiments from several previous studies were used (Table 157 S2). One andesite glass doped with $0.13 \mathrm{wt} \% \mathrm{MoO}_{3}$ was analyzed from Righter et al. (1998), a 158 product that was melted in air (Table S1). This sample was used as a good representative of a $159 \mathrm{Mo}^{6+}$ glass. Righter and Drake (1999) carried out D(Mo) metal-silicate partitioning experiments 160 with hawaiite melts and FeNiMo alloys at $1 \mathrm{GPa}, 1300{ }^{\circ} \mathrm{C}$ and near IW buffer. These 161 experimental glasses contain low concentrations of Mo from $0.11 \mathrm{ppm}$ to $11.78 \mathrm{ppm}$ by weight 162 (Righter and Drake, 1999). In addition, a series of glasses from piston cylinder experiments of 163 Righter et al. (2010) used a hawaiite silicate composition (Table S1), and were run at higher 164 temperature (1500-1900 $\left.{ }^{\circ} \mathrm{C}\right)$ and lower $\mathrm{fO}_{2}$ (IW-1.4). Finally, Righter et al. (2013) carried out 165 experiments on a synthetic shergottite basaltic glass (Table S1) in Mo capsules from 1 to $4 \mathrm{GPa}$ 166 (Mo-1, -2, -2B, -4A, and BJJB-187); these experimental glasses contain appreciable amounts of 167 Mo and allowed Mo valence to be measured at intermediate pressures to some of the other 168 studies at higher and lower pressure.

\section{Analyses}

Electron microprobe analysis (EMPA)

171 Glasses and metals from the run products were analyzed with an electron microprobe for 172 major elements with a CAMECA SX100 electron microprobe, using an accelerating voltage of $17320 \mathrm{kV}$ and sample current of 20 to $40 \mathrm{nA}$ (see additional details in Righter et al., 2010). Carbon 174 in metallic phases was analyzed using the standards and approach of Dasgupta et al. (2013), and 175 all elemental abundances were re-calculated using the measured $\mathrm{C}$ contents in the matrix 176 corrections. Multiphase quenched silicate melt and metallic melt were analyzed by rastering the 177 beam over a $10 \times 10$ micron area, for 20 to 50 different regions that were then averaged. 
178 Traverses from capsule wall to metal sphere show no variation in composition. Micro-sized 179 metal flakes are visible and were avoided by using BSE imaging. Typical uncertainty for major 180 elements analyzed by the NASA-JSC electron microprobe is $<2 \%$, and for Mo and P in metals < $1815 \%$. Results of the analyses are presented in Table S3 and S4.

182 Laser ablation inductively coupled plasma mass spectrometry (LA-ICP-MS)

183 Mo concentrations at very low concentrations (<100 ppm detection limits of EMPA) were 184 obtained by laser ablation inductively coupled plasma mass spectrometry (ICP-MS) at Rice 185 University using ThermoFinnigan Element 2 ICP-MS coupled to a New Wave $213 \mathrm{~nm}$ laser 186 ablation system (Agranier and Lee, 2007). Analyses were performed in medium mass resolution $187(\mathrm{~m} / \Delta \mathrm{m}=3500)$ in order to resolve all major isobaric molecular interferences. Isotopes analyzed 188 were both ${ }^{95} \mathrm{Mo}$ and ${ }^{97} \mathrm{Mo}$ (Table S2) for additional assurance that interferences were negligible. 189 Drift of mass calibration was corrected by centering on the ${ }^{40} \mathrm{Ar}^{40} \mathrm{Ar}^{+}$dimer in each 190 measurement. The laser was set at $10 \mathrm{~Hz}$ pulse frequency and an energy density of $10 \mathrm{~mJ} / \mathrm{cm}^{2}$. 191 Measurements consisted of about 10 analyses of gas flow background followed by 40-50 192 measurements of the ablation signal. Gas background was averaged and then subtracted from 193 ablation signal. Background-corrected signals were converted to concentrations using a 194 combination of internal and external standards. ${ }^{25} \mathrm{Mg}$ was used as an internal standard for 195 glasses and quenched silicate liquids. USGS basaltic glass standards (BHVO2g, BCR2g) and 196 NIST glasses (610 and 612) were used as external standards for the silicate glasses (Gao et al., 197 2002; see Table S5, Supplementary Information). Finally, the limit of detection for each 198 analysis was estimated at 3 times the standard deviation of the background divided by the 199 sensitivity of the instrument as monitored by ${ }^{25} \mathrm{Mg}$ (see also Agranier and Lee, 2007), and 
uncertainties are typically $\sim 5 \%$ of the amount present $(1 \sigma)$. Micro-sized metal flakes are visible and were avoided by using BSE imaging; as with studies of highly siderophile elements, these flakes are common and are interpreted to be present at high PT conditions rather than forming on quench (Malavergne et al., 2016), and so they are avoided during the analyses for Mo. For partition coefficients, this corresponds to a typical uncertainty of $10 \%(1 \sigma)$ on the reported values of the partition coefficient; these are the error bars presented in the figures.

\section{$X$-ray absorption near edge spectroscopy (XANES)}

A monochromatic X-ray beam from a $\mathrm{Si}(111)$ double crystal monochromator was focused onto the sample and the fluorescent X-ray yield was plotted as a function of incident Xray energy (see for example, Sutton et al., 2002). A Vortex ME4 silicon drift energy dispersive detector was used to collect the Mo K fluorescence. Energy calibration was set to $20000.0 \mathrm{eV}$ for the first derivative peak of the Mo metal foil spectrum. Mo K XANES spectra were typically collected with $3 \mathrm{sec}$ dwell times scanning the incident energy (relative to $20000.0 \mathrm{eV}$ ) from -50 to $-10 \mathrm{eV}$ in $5 \mathrm{eV}$ steps, -10 to $30 \mathrm{eV}$ in $0.25 \mathrm{eV}$ steps and 2.8 to $9.0 \mathrm{in} k\left(\AA^{-1}\right)$ in 0.1 steps. The resulting XANES spectra were corrected for detector dead time then normalized so that the below edge intensity was zero and the above edge intensity was unity.

Mo valences were obtained using a linear combination approach based on full XANES spectra. For optimum fitting, end member spectra from the experimental samples were used as standards. The $\mathrm{Mo}^{6+}$ standard was the ankaramite IW+2 spectrum whose edge energy was found to match that of $\mathrm{MoO}_{3}$. We observed two different spectra in the reduced samples with neutral Mo edge positions - because these two components may reflect different neutral coordinations in the glass, we included them both as components in the fits. Two different "cow" spectra were 
222 thus used as $\mathrm{Mo}^{0}$ standards, IW-5 and IW-2.8, with fit results presented as $\mathrm{Mo}^{0 \mathrm{a}}$ and $\mathrm{Mo}^{0 \mathrm{~b}}$, 223 respectively, in Table 1. Both spectra had edge energies similar to that of Mo metal but with 224 distinct detailed structure. The neutral Mo differences may be due to coordination effects, Mo 225 alloying, or possibly grain size effects. The best $\mathrm{Mo}^{4+}$ standard was ankaramite IW-2 which had 226 an effective valence of 4.34 based on edge energy comparison with a spectrum of $\mathrm{MoO}_{2}$. A 227 synthetic $\mathrm{Mo}^{4+}$ standard spectrum was produced by subtracting $17 \%$ of the $\mathrm{Mo}^{6+}$ standard 228 spectrum (ankaramite IW+2). Fits were carried out using Athena (Ravel and Newville, 2005) 229 and the uncertainties in the component weights reported by Athena are its best estimates of the 1 230 sigma values. Several examples of the results of this linear combination fitting are shown in 231 Figure 2 and all are presented in Table 1.

The most reduced experiments contained glass with very low concentration of Mo 233 (several ppm) and visible metal flakes. Initial XANES measurements on glassy regions in the 234 thick mounts resulted in a large metal Mo (zero valent) component in the spectra, indicating the 235 likely contribution of the metal flakes to the spectra, and thus a compromised measurement with 236 higher uncertainty. To counter this problem, we prepared thin sections of these reduced 237 problematic samples. The thin sections allowed us to select regions that are visibly free of 238 metallic flakes, not only at the surface (visible with reflected light in the thick mount) but also at 239 depths through the 30 to 50 micron thickness of the sample. The Mo microdistribution in these 240 regions was then mapped by XRF and final analysis spots selected as those isolated from Mo hot 241 spots. XANES analyses of these specially selected spots that are free of interfering metallic 242 flakes yielded much better spectra that were relatively free of the $\operatorname{Mo}(0)$ component, and yielded 243 more reliable fits to the $\mathrm{Mo}^{4+}$ and $\mathrm{Mo}^{6+}$ components that were present. Images and spectra for 
244 several of these samples are presented in the Supplementary Information (Figs S1 to S7), and

245 results presented in Table 1, along with all other results.

247 Results

248 Equilibrium and oxygen fugacity

Several lines of evidence can be used to assess whether equilibrium was approached in 250 these experiments. First, if the reaction of metal with silicate did not reach completion or 251 equilibrium, there will be variable silicate compositions according to the equilibrium $2 \mathrm{Fe}+$ $252 \mathrm{Mg}_{2} \mathrm{SiO}_{4}+\mathrm{O}_{2}=2 \mathrm{MgO}+\mathrm{Fe}_{2} \mathrm{SiO}_{4}$ and one might expect to find zoned metal or olivine. 253 However, the silicates and metals are not compositionally zoned, indicating that equilibrium has 254 been attained (see Tables S3, S4). Second, the experiments are very similar in design and 255 duration to experiments of Righter et al. (2010) in which a time series was performed. The 256 duration of the new experiments is longer than the time required for equilibrium defined by these 257 previous experiments (see Table S2). Finally, the experiments reported here are also longer than 258 experiments for which time series have been done for slower diffusing elements such as $\mathrm{Mo}^{4+}$ 259 and $\mathrm{Mo}^{6+}$ (Righter et al., 1997; Righter and Drake, 1999, 2000).

260 As mentioned above, Si metal was added to experiments to promote more reduced conditions 261 - Si alloys with Fe at high temperatures, an approach that has been used for example by Berthet 262 et al. (2009) and others to produce a reduced environment in high pressure sample assemblies. 263 An increase in $\mathrm{Si}$ content will cause a decrease in $\mathrm{fO}_{2}$. Oxygen fugacity was calculated relative 264 to the iron-wüstite (IW) oxygen buffer using the expression $\Delta \mathrm{IW}=-2 * \log \left[\mathrm{a}_{\mathrm{Fe}} / \mathrm{a}_{\mathrm{FeO}}\right]$, where $\mathrm{a}_{\mathrm{Fe}}$ 265 was calculated using the MetalAct program (see Wade and Wood, 2005) and $\mathrm{a}_{\mathrm{FeO}}$ is calculated 
according to Holzheid et al. (1997) where $\gamma_{\mathrm{FeO}}=1.6$ for the melts considered in this study. The $\Delta \mathrm{IW}$ values ranged from $\sim-1.44$ for $\mathrm{Si}$ free runs compared to $\mathrm{Si}$ bearing runs which produced $\Delta \mathrm{IW}$ values as low as -5 (Table $\mathrm{S} 2$ ). The range of $\Delta \mathrm{IW}$ values for these experiments falls in the range considered during Earth's core formation (-1 to -5).

\section{Glass and metal elemental compositions}

The Fe-rich metallic liquid contained between 0.8 and 5.2 wt $\%$ Mo, in addition to Fe. In the series with variable $\mathrm{Si}$ content, the metallic liquids contained as much as $7.2 \mathrm{wt} \% \mathrm{Si}\left(\mathrm{X}_{\mathrm{Si}}=\right.$ 0.13; Table S3). Carbon contents ranged from 2.8 to $6.2 \mathrm{wt} \%$; carbon is lower in the Si-bearing metallic liquids because in the $\mathrm{Fe}-\mathrm{Si}-\mathrm{C}$ system the FeSi-rich liquids contain less $\mathrm{C}$ than $\mathrm{Fe}$-rich liquids in the $\mathrm{Fe}-\mathrm{C}$ system.

The glasses produced are typically basaltic glasses with 11.7 to $23.2 \mathrm{wt} \% \mathrm{MgO}$ and 40 to $50 \mathrm{wt} \% \mathrm{SiO}_{2}$ (Table $\mathrm{S} 3$ and $\mathrm{S} 4$ ). $\mathrm{FeO}$ contents are variable with $\mathrm{fO}_{2}$; the lowest $\mathrm{fO}_{2}$ experiments (Cow D and C; Table S3) contain $\sim 0.1 \mathrm{wt} \% \mathrm{FeO}$, whereas the higher $\mathrm{fO}_{2}$ experiments contain as much as $13.3 \mathrm{wt} \% \mathrm{FeO}$ (Table S4). The Mo contents of the glasses are also variable with doping levels and oxygen fugacity. The Mo solubility ankaramite glasses contain from 700 to 13,700 ppm of Mo - these melts were doped with Mo and equilibrated with Re wire and thus had higher final Mo contents. The Mo solubility basalt series was un-doped, equilibrated at variable $\mathrm{fO}_{2}$ and contained 1.6 to $90 \mathrm{ppm}$ Mo. In each series the highest Mo contents were measured in the highest $\mathrm{fO}_{2}$ of equilibration (> IW; Table S2). In the $1 \mathrm{GPa}$ partitioning experiments, Mo contents of the glasses were lowest in the low $\mathrm{fO}_{2}$ experiments, 0.2 to $0.5 \mathrm{ppm}$, compared to the higher $\mathrm{fO}_{2}$ runs in which Mo contents were $>4.0 \mathrm{ppm}$ (Table S1, S2 and Righter et al., 2010). In the BJJB multi-anvil experiments, Mo contents were considerably higher, and ranged from 100 
289 to $185 \mathrm{ppm}$. And, for the GN series multi-anvil experiments (from Shofner, 2011), Mo contents 290 are between 34 and 90 ppm (Table S2).

291 Glass Valences

292 Examination of the effective valence in many of the results from this study shows that 293 many of the samples exhibit evidence for lower valence than 4 (Table 1). Although it is possible 294 that lower valences exist, we attribute this effect to the possibility of interfering metal flakes in 295 the silicate melts. Because Mo has a very low solubility in silicate melts, Mo metal saturates in 296 silicate melt very easily. In some samples there are metal flakes present and in many of the run 297 products the metal undoubtedly interferes with the XANES analyses of the glass. Because Mo $^{0}$, $298 \mathrm{Mo}^{4+}$ and $\mathrm{Mo}^{6+}$, all have distinct spectral features, each spectrum can be fit with a linear 299 regression, to determine what proportion of each species is represented (see previous XANES 300 methods section). When the contribution of interfering metal flakes are subtracted from the 301 overall spectrum, the $\mathrm{Mo}^{6+}$ to $\mathrm{Mo}^{4+}$ contents, or "non-metal" valence, can be determined. These 302 are shown in Figure 3.

Partition coefficients

The very low solubilities of Mo in the glasses from the series of partitioning experiments 305 with Si-bearing metal result in very high partition coefficients for Mo. Values range from 270 to 3067200 in the $\mathrm{Si}$-free samples to 34,000 to 137,400 in the Si-bearing samples. For the high 307 pressure experiments, D(Mo) ranges from 96 to 250 (Table S2).

\section{Discussion}

Valence - effect of $\mathrm{fO}_{2}$ and elevated pressure and temperature 
After the effect of metallic Mo is corrected, the "non-metal" valence can be re-examined

311 for systematic behavior. In particular the transition from $\mathrm{Mo}^{6+}$ to $\mathrm{Mo}^{4+}$ can be studied.

312 Considering only those spectra from 1 bar glasses where the metal contributions were less than

$31350 \%$ (i.e., where there is higher reliability in fitting the non-metal component), one can see that

314 there is a fairly nice trend transitioning between $6+$ and $4+$ over about 3 orders of magnitude

315 centered at about IW-0.5 (Fig. 3a). Thus, the transition from $\mathrm{Mo}^{6+}$ to $\mathrm{Mo}^{4+}$ occurs largely

316 between IW and IW-1, in good agreement with the 1 bar studies of Holzheid et al. (1994) and

317 O’Neill and Eggins (2002), who concluded Mo changed dominant valence from $\mathrm{Mo}^{6+}$ to $\mathrm{Mo}^{4+}$ at $^{4}$

318 around IW-1 (Fig. 3a). Calculation of a hypothetical transition of Mo from 4+ to 6+ centered at

319 IW-0.5 and based on the 2-electron transition of $\mathrm{Mo}^{4+} \mathrm{O}_{2}+1 / 2 \mathrm{O}_{2}=\mathrm{Mo}^{6+} \mathrm{O}_{3}$, results in a curve

320 that closely corresponds to our data in this $\mathrm{fO}_{2}$ range (Fig. 3b). At the conditions of core

321 formation, near IW-2, $\mathrm{Mo}^{6+}$ is present only at trace levels. Farges et al. (2006) suggested $\mathrm{Mo}^{5+}$

322 may be stable around IW, but Farges' et al. (2006) evidence for stable $\mathrm{Mo}^{5+}$ (determined from

323 additional electron paramagnetic resonance spectroscopy data) appears only in FeO-free systems.

324 It is thus more likely that we have a mixture of $\mathrm{Mo}^{4+}$ and $\mathrm{Mo}^{6+}$ across a small $\mathrm{fO}_{2}$ range, yielding

325 to predominately $\mathrm{Mo}^{4+}$ at IW-2 and below. In addition, there may be quench effects involving

326 redox couples such as have been observed for $\mathrm{Cr}$ and Fe in experimental studies (Berry et al.,

327 2004). In that experiment, the reaction $\mathrm{Cr}^{2+}+\mathrm{Fe}^{3+} \rightarrow \mathrm{Cr}^{3+}+\mathrm{Fe}^{2+}$ was hypothesized to be

328 operating at IW+2 causing oxidation of $\mathrm{Cr}^{2+}$ to $\mathrm{Cr}^{3+}$ during quench. In our experiments, it is

329 possible that the reaction $\mathrm{Fe}^{3+}+\mathrm{Mo}^{4+} \rightarrow \mathrm{Fe}^{2+}+\mathrm{Mo}^{6+}$ could have operated during quench,

330 causing oxidation of $\mathrm{Mo}^{4+}$ to $\mathrm{Mo}^{6+}$, but at IW there is very little $\mathrm{Fe}^{3+}$ stable in FeO-bearing melts

331 (Righter et al., 2013); in the ankaramite series, for example, the Mo contents range from 700 to

$33214000 \mathrm{ppm} \mathrm{Mo}$, much higher than $\mathrm{Fe}^{3+}$ expected at these low $\mathrm{fO}_{2}$ conditions. Nonetheless 
333 oxygen fugacity of the $\mathrm{Mo}^{4+}$ to $\mathrm{Mo}^{6+}$ transition determined in the present study can be considered 334 a conservative lower limit.

335 The measurements made on high pressure and high temperature glasses indicate that $336 \mathrm{Mo}^{4+}$ is dominant at oxygen fugacity below IW-1 (Fig. 4). At temperature between 1500 and $3371800{ }^{\circ} \mathrm{C}$, Mo valence is lowered from 6 to $<5$, and then at 2000 to $2200{ }^{\circ} \mathrm{C}$, the valence is 4 (Fig 338 4a). High pressure glasses between 12 and 24 GPa and IW-1.5 exhibit a valence of 4, whereas 339 lower pressure glasses at IW+0.5 contain Mo dominated by valence of 6 (Fig. 4b). Note that 340 experiment Mo-2 yielded $\mathrm{Mo}^{4+}$ spectrum at $1 \mathrm{GPa}$, but this experiment contained small crystals 341 of $\mathrm{MoO}_{2}$ and the spectrum for this glass had a strong resemblance to $\mathrm{MoO}_{2}$, leading us to the 342 conclusion that this sample should be omitted from the glass valence assessments. There is no 343 particular correlation between Mo content of glass and valence with the exception of the 344 ankaramite series in which the Mo contents increase with valence due to the increasing solubility 345 of Mo in equilibrium with the Mo foil at higher $\mathrm{fO}_{2} \mathrm{~s}$. The main factor in determining valence is 346 oxygen fugacity.

\section{Effect of Si in Fe metal}

The effect of Si on Mo partitioning between metal and silicate can be examined using

349 four experiments from this study (cow B1, C2, D1, 3), coupled with the Fe exchange coefficient $350 \quad \mathrm{~K}_{\mathrm{d}}(\mathrm{Fe}-\mathrm{Mo})$ based on the equilibrium:

$$
2 \mathrm{Fe}+\mathrm{MoO}_{2}=2 \mathrm{FeO}+\mathrm{Mo}
$$

352 This equilibrium is independent of oxygen fugacity, and therefore can be used to isolate the 353 effect of Si on Mo partitioning. Consider that 
$354 \ln \mathrm{K}=\ln \frac{\left[a_{\mathrm{Mo}}^{\text {metal }}\right]\left[a_{\mathrm{FO}}^{\text {silicate }}\right]^{2}}{\left[a_{\mathrm{MoO} 2}^{\text {silicate }}\right]\left[a_{\mathrm{Fe}}^{\text {metal }}\right]^{2}}=\ln \frac{\left[X_{\mathrm{Mo}}^{\text {metal }}\right]\left[X_{\mathrm{FeO}}^{\text {silicate }}\right]^{2}}{\left[X_{\mathrm{MoO} 2}^{\text {silicate }}\right]\left[X_{\mathrm{Fe}}^{\text {metal }}\right]^{2}}+\ln \frac{\left[\gamma_{\mathrm{Mo}}^{\text {metal }}\right]\left[\gamma_{\mathrm{FeO}}^{\text {silicate }}\right]^{2}}{\left[\gamma_{\mathrm{MoO} 2}^{\text {silicate }}\right]\left[\gamma_{\mathrm{Fe}}^{\text {metal }}\right]^{2}}$

355 where $a$ refers to activity, $X$ refers to mole fraction, and $\gamma$ refers to the activity coefficient. We

356 set $\mathrm{K}_{\mathrm{D}}=\frac{\left[X_{\mathrm{Mo}}^{\text {metal }}\right]\left[X_{\mathrm{FeO}}^{\text {silicate }}\right]^{2}}{\left[X_{\mathrm{MoO} 2}^{\text {silicate }}\right]\left[X_{\mathrm{Fe}}^{\text {metal }}\right]^{2}}$ and assume the ratio of oxide activity coefficients in the silicate,

$357 \frac{\left[\gamma_{\mathrm{FeO}}^{\text {silicate }}\right]^{2}}{\left[\gamma_{\mathrm{MoO} 2}^{\text {silicate }}\right]}$, is fixed, since in this series the silicate melt composition is nearly constant from 358 experiment to experiment (see expts. cow-B1, -C2, -D1, and -3 all with $(\mathrm{MgO}+\mathrm{CaO}) /\left(\mathrm{SiO}_{2}+\right.$ $359 \mathrm{Al}_{2} \mathrm{O}_{3}$ ) values between 0.55 and 0.7 ). On the other hand, the metal composition varies

360 significantly in $\mathrm{Si}$ content and the ratio of activity coefficients in the metal, $\frac{\left[\gamma_{M o}^{\text {metal }}\right]}{\left[\gamma_{\mathrm{Fe}}^{\text {metal }}\right]^{2}}$, is

361 dependent upon variations in metal composition. Then equation (2) above can be re-arranged to 362 yield $\ln K_{\mathrm{D}}=\mathrm{const}+2 \ln \gamma_{F e}^{\text {metal }}-\ln \gamma_{M o}^{\text {metal }}$. And when combined with $\ln \gamma_{M o}^{\text {metal }}=\ln \gamma_{F e}^{\text {metal }}+\ln \gamma_{M o^{-}}^{0}$ $363 \varepsilon_{M o}^{S i} \ln \left(1-\mathrm{X}_{\mathrm{Si}}\right)$ yields:

364

$$
\ln K_{\mathrm{D}}-\ln \gamma_{F e}^{m e t a l}=\mathrm{const}-\ln \gamma_{M o}^{0}+\varepsilon_{M o}^{S i} \ln \left(1-\mathrm{X}_{\mathrm{Si}}\right)
$$

365 where $\varepsilon_{M o}^{S i}$ refers to the interaction parameter for Mo in Si alloyed with Fe (Wagner, 1962; Wade 366 and Wood, 2005; Ma, 2001; Wood et al., 2014).

367 The slope of $\ln \mathrm{K}_{\mathrm{D}}-\ln \gamma_{F e}^{\text {metal }}$ versus $\ln \left(1-\mathrm{X}_{\mathrm{Si}}\right)$ gives $\varepsilon_{M o}^{S i}$ directly (Figure 5). Slopes were 368 determined by linear regression using SigmaStat 12.0. The resulting value of $62( \pm 12)$ is in 369 agreement with the previous work of Ono-Nakazato et al. (2007), whose value is $43( \pm 13)$, but 370 higher than reported by Tuff et al. (2011) whose value is $22( \pm 5)$. This difference may be due to 371 the presence of $\mathrm{C}$ in our experiments and those of Ono-Nakazato et al. (2007), compared to the 372 C-free experiments of Tuff et al. (2011). Even though several of our points fall along the trend 
373 of Tuff et al. (2011), the two points at very low Si content (but significantly different C content)

374 show an important effect of $\mathrm{C}$, therefore these two data sets should not be combined; the overlap

375 in our two points is coincidental. The effect of $\mathrm{Si}$ is to reduce the $\ln \mathrm{K}_{\mathrm{d}}(\mathrm{Fe}-\mathrm{Mo})$ from values near

3766 to as low as -2 (Figure 5). This magnitude of reduction is important to quantify and is larger

377 than the effect of $\mathrm{S}$ or $\mathrm{C}$ on Mo partitioning documented in previous work (e.g., Jana and

378 Walker, 1997a,b; Righter and Drake, 1999). The value of epsilon can be used as an indicator of

379 the effect of S on activity coefficient, and for comparison the recent work of Wood et al. (2014)

380 measured $\varepsilon_{M o}^{S}=2.27$. Because the Earth's core was not C-saturated we use the value $\varepsilon_{M o}^{S i}=22$

381 in all of our subsequent modelling.

382 The effect of pressure

The effect of pressure can be examined combining our results with previous high

384 pressure experiments - above and below the pressures of our study. As with the examination of 385 the effect of $\mathrm{Si}$, the use of $\mathrm{K}_{\mathrm{d}}(\mathrm{Fe}-\mathrm{Mo})$ instead of $\mathrm{D}(\mathrm{Mo})$ will eliminate any variation that is due to 386 different $\mathrm{fO}_{2}$ of the experiments being compared. When the $\ln \mathrm{K}_{\mathrm{d}}(\mathrm{Fe}-\mathrm{Mo})$ from these 387 experiments are plotted versus pressure, it is clear that pressure causes a slight decrease in ln $388 \mathrm{~K}_{\mathrm{d}}(\mathrm{Fe}-\mathrm{Mo})$, on the order of one $\ln \mathrm{K}_{\mathrm{d}}$ units at $25 \mathrm{GPa}$ (Fig. 6). Our data are consistent with the 389 trend defined by previous works of Hillgren et al. (1996), Siebert et al. (2011) and Wade et al. 390 (2012). Our new results double the number of experimental data available for Mo at pressure > $39110 \mathrm{GPa}$.

\section{$392 \quad$ Prediction of $\mathrm{D}(\mathrm{Mo}) \mathrm{met} / \mathrm{sil}$}

To predict the metal-silicate partitioning of Mo for application to Earth, we will use the partition coefficient, or D, approach based on a simple metal-oxide equilibrium: 
396 Considering that $\Delta \mathrm{G}=-\mathrm{RT} \ln \mathrm{K}$, and expanding the free energy term to $\Delta \mathrm{H}-\mathrm{T} \Delta \mathrm{S}+\mathrm{P} \Delta \mathrm{V}=-$ 397 RTlnK, and the equilibrium constant to $\mathrm{K}=\left(\mathrm{aMO}_{\mathrm{x} / 2}\right) /(\mathrm{aM})\left(\mathrm{fO}_{2}\right)=$ $398\left(\gamma \mathrm{MO}_{\mathrm{x} / 2} * \mathrm{xMO}_{\mathrm{x} / 2}\right) /(\gamma \mathrm{M} * \mathrm{xM})\left(\mathrm{fO}_{2}\right)$. And recombining equals $-\Delta \mathrm{H} / \mathrm{RT}+\Delta \mathrm{S} / \mathrm{R}-\mathrm{P} \Delta \mathrm{V} / \mathrm{RT}=\ln$ $399\left[\left(\gamma \mathrm{MO}_{\mathrm{x} / 2} * \mathrm{xMO}_{\mathrm{x} / 2}\right) /(\gamma \mathrm{M} * \mathrm{xM})\left(\mathrm{fO}_{2}\right)\right]=\ln \left(\gamma \mathrm{MO}_{\mathrm{x} / 2}\right)-\ln \gamma \mathrm{M}+\ln x \mathrm{MO}_{\mathrm{x} / 2} / \mathrm{xM}-\operatorname{lnfO} \mathrm{O}_{2}$. Rearranging 400 yields:

$$
\ln \left(\mathrm{xM} / \mathrm{xMO}_{\mathrm{x} / 2}\right)=(\Delta \mathrm{H} / \mathrm{R}) / \mathrm{T}-\Delta \mathrm{S} / \mathrm{R}-+(\Delta \mathrm{V} / \mathrm{R}) \mathrm{P} / \mathrm{T} . \operatorname{lnfO} \mathrm{O}_{2}+\ln \left(\gamma \mathrm{MO}_{\mathrm{x} / 2}\right)-\ln \gamma \mathrm{M},
$$

and substituting $\mathrm{D}(\mathrm{M})=\mathrm{xM}^{\text {metal }} / \mathrm{xMO}_{\mathrm{x} / 2}$ silicate, the expression becomes:

$$
\ln \mathrm{D}(\mathrm{M})=\mathrm{alnfO}_{2}+\mathrm{b} / \mathrm{T}+\mathrm{cP} / \mathrm{T}+\ln (\gamma \mathrm{MO} \gamma)-\ln \gamma \mathrm{M}+\text { const. }
$$

404 Using this approach, and incorporating silicate liquid compositional term nbo/t as a proxy for the 405 activity coefficient of species $\mathrm{M}$ in silicate melt, $\ln \left(\gamma \mathrm{MO}_{\mathrm{x} / 2}\right)$, equation (6) becomes:

$$
\ln \mathrm{D}(\mathrm{M})=\mathrm{alnfO}_{2}+\mathrm{b} / \mathrm{T}+\mathrm{cP} / \mathrm{T}+\mathrm{d}(\mathrm{nbo} / \mathrm{t})+\mathrm{e}+\ln \gamma(\mathrm{M})_{\text {met }}
$$

$$
\ln { }^{\prime}(\mathrm{M})=\ln \mathrm{D}(\mathrm{M})-\ln \gamma(\mathrm{M})_{\mathrm{met}}=\mathrm{alnfO}_{2}+\mathrm{b} / \mathrm{T}+\mathrm{cP} / \mathrm{T}+\mathrm{d}(\mathrm{nbo} / \mathrm{t})+\mathrm{e}
$$

408 Constants a through e can be derived by multiple linear regression of existing experimental data. 409 Equation (4) is clearly dependent upon $\mathrm{fO}_{2}$, and so is most effectively applied when the valence 410 is constant. Again, this can be used as long as the valence is dominantly 4, and thus using 411 experiments that were equilibrated at $<\mathrm{IW}-1 . \mathrm{fO}_{2}$ is calculated using the IW buffer of Campbell 412 et al. (2009) along with activity of Fe using MetAct (Wade and Wood, 2005; Ma, 2001) and 413 activity coefficient of $\mathrm{FeO}$ in silicate melt (as explained above). 
415 from this study, 35 experiments from Siebert et al. (2011) between 1.5 and $18 \mathrm{GPa}, 1600$ to

$4162600{ }^{\circ} \mathrm{C}$, and C-bearing metals; 46 experiments from Wade et al. (2012) between 1.5 and 24

$417 \mathrm{GPa}, 1475$ to $2450{ }^{\circ} \mathrm{C}, \Delta \mathrm{IW}=-0.9$ to $-3.4 ; 20$ experiments from Tuff et al. (2011) at 1650 to

$4181850{ }^{\circ} \mathrm{C}, 1.5$ to $6 \mathrm{GPa}$ and with variable $\mathrm{Si}$ in metallic liquids; 10 experiments from Righter et al.

419 (2010) at $1 \mathrm{GPa}, 1500$ to $1900{ }^{\circ} \mathrm{C}$ and variable silicate melt compositions, 2 experiments from

420 Hillgren et al. (1996) and $10 \mathrm{GPa}$, and $2000{ }^{\circ} \mathrm{C} ; 14$ experiments from Walter and Thibault

421 (1995) 1800 to $2400{ }^{\circ} \mathrm{C}$, and 1 to $7 \mathrm{GPa}$ with $\mathrm{C}$-bearing metallic liquids; 13 experiments from

422 Righter et al., (1997) and Righter and Drake (1999) at $1 \mathrm{GPa}$ and $1300{ }^{\circ} \mathrm{C}, 2$ experiments from

423 Jana and Walker (1997a,b) at $8 \mathrm{GPa}, 2300{ }^{\circ} \mathrm{C}$; and 3 experiments from Wade and Wood (2001)

424 at $25 \mathrm{GPa}$ and $2300{ }^{\circ} \mathrm{C}$. Altogether there are 155 experiments utilized covering 1 to $25 \mathrm{GPa}$,

4251300 to $2600{ }^{\circ} \mathrm{C}, \Delta \mathrm{IW}=-1$ to $-6.8, \mathrm{~S}-, \mathrm{C}-$, and Si-bearing metallic liquids, and basaltic to

426 peridotitic silicate melt. The result of the regression is shown in Figure S10 (Supplementary

427 Information) and regression coefficients presented in Table S6. The uncertainties on each

428 coefficient are measures of the precision of the estimates of the regression coefficients.

429 Traditional statistical tests such as $\mathrm{R}^{2}$ (coefficient of determination), $\mathrm{t}$ values, $\mathrm{P}$ values, and $\mathrm{F}$

430 statistics are used to evaluate the quality of the regressions and the significance of each term.

431 Derivation of an $\mathrm{fO}_{2}$ coefficient (a) value near -1 indicates that Mo is dominantly $4+(\mathrm{a}=-1.5$

432 would indicate 6+), which is consistent with our XANES results. The pressure term in the

433 regression is consistent with the magnitude of the effect in Figure 6. The effect of $\mathrm{C}$ dissolved

434 into the metallic liquid is to increase $\ln \mathrm{D}(\mathrm{Mo})$, whereas the effect of dissolved $\mathrm{S}$ and $\mathrm{Si}$ is to 435 decrease $\ln \mathrm{D}(\mathrm{Mo})$. The effect of $\mathrm{Si}$ is much stronger than the effect of $\mathrm{S}$. The melt 436 compositional terms are in agreement and in general show increase in $\ln \mathrm{D}(\mathrm{Mo})$ with higher $\mathrm{Si}$ 
437 and $\mathrm{Al}$ content and a decrease in $\operatorname{lnD}(\mathrm{Mo})$ higher $\mathrm{Mg}$ or $\mathrm{Ca}$ contents. We will now consider 438 application of these expressions to the Earth's mantle.

440 Application to Earth

441

442

443

444

445

446

447

448

449

450

451

452

453

454

455

456

457

Defining the $\mathrm{D}(\mathrm{Mo})$ and $\mathrm{K}_{d}(\mathrm{Fe}-\mathrm{Mo})$ required for core-mantle equilibrium

Using geochemical data and estimates for the core and mantle Fe and Mo compositions, $\mathrm{K}_{\mathrm{d}}(\mathrm{Fe}-\mathrm{Mo})$ and $\mathrm{D}(\mathrm{Mo})$ required to explain the upper mantle Mo content by metal-silicate equilibrium can be calculated. Using $\mathrm{Fe}$ and $\mathrm{FeO}$ content of core and mantle $(85.5 \mathrm{wt} \%$ and 8.0 wt\%, respectively; McDonough, 2013) and Mo content of core and mantle (5 ppm and $27 \mathrm{ppb}$, respectively; McDonough, 2013; Greber et al., 2015), $\ln \mathrm{K}_{\mathrm{d}}(\mathrm{Fe}-\mathrm{Mo}$ ) (molar) required to explain the $\mathrm{FeO}$ and $\mathrm{MoO}_{2}$ content of primitive mantle is $0.17\left(\ln \mathrm{K}_{\mathrm{d}}(\mathrm{Fe}-\mathrm{Mo})=-1.71\right)$. Similarly, using the Mo content of upper mantle $27 \mathrm{ppb}$; and Mo estimate for the core (based on mass balance and assuming a range of chondrite compositions from CI to EH; Newsom, 1995), required $\mathrm{D}(\mathrm{Mo})$ is $\sim 60$ to 120 . These values will be used in detailed modelling presented below.

\section{Calculation of $\mathrm{D}(\mathrm{Mo}), \mathrm{D}^{\prime}(\mathrm{Mo})$, and [Mo] in mantle as Earth accretes}

\section{Recent magma ocean modeling indicates moderately siderophile element depletions in Earth's} primitive upper mantle can be explained by metal-silicate equilibrium between metallic and silicate liquid at high PT conditions during Earth's accretion $\left(\sim 40 \mathrm{GPa}, \sim 3600{ }^{\circ} \mathrm{C}\right.$; e.g., Righter, 2011; Wade et al., 2012; Siebert et al., 2011). There is some debate about the specific PT conditions, and whether the oxygen fugacity in the mantle changed during accretion or was relatively constant. Modeling suggests that $\mathrm{fO}_{2}$ started low and eventually became higher during 
accretion (e.g., Wood et al., 2006; Rubie et al., 2011), whereas some recent calculations indicate that $\mathrm{fO}_{2}$ may have decreased (Badro et al. 2015; Siebert et al., 2013) or changed only slightly during accretion (Righter and Ghiorso, 2012a,b). If the oxygen fugacity is changing during accretion, the core forming metallic liquid will also change because reduced conditions will favor Si dissolution, whereas oxidized conditions will favor S or C. These light elements will exert a strong effect on the activity coefficients of each trace metal as we have seen in this study and discussed above.

Due to this uncertainty in the $\mathrm{fO}_{2}$ evolution of the growing Earth, we examine the evolution of the composition of the Earth's PUM during continuous accretion considering two scenarios: one with nearly constant $\mathrm{fO}_{2}$ (IW-2) and one with increasing $\mathrm{fO}_{2}$ (IW-4 to IW-2). The core metallic liquid S, C, and Si composition is calculated according to the studies of Boujibar et al. (2014), Chi et al. (2014), and Ricolleau et al. (2011), respectively (Figure 7). Calculations have been carried out along the PT conditions of the liquidus for peridotite, according to Andrault et al. (2011). Equilibration between metal and silicate in Earth occurs instantaneously so that as the Earth grows there is constant re-equilibration between the core and mantle (e.g., Deguen et al., 2014; Kendall and Melosh, 2014). The equation used to calculate mantle Mo concentrations is:

$$
C_{L S}^{M o}=C_{b u l k}^{M o} / x\left[p+(1-p) D_{S S / L S}^{M o}\right]+(1-x)\left[D_{L M / L S}^{M o}\right]
$$

Where $\mathrm{x}$ is the fraction of silicate, $\mathrm{p}$ is the fraction of molten silicate, $C_{b u l k}^{M o}$ is the bulk concentration of Mo, $C_{L S}^{M o}$ is the concentration of Mo in the liquid silicate, $D_{S S / L S}^{M o}$ is the partition coefficient between solid silicate and liquid silicate, and $D_{L M / L S}^{M o}(=\mathrm{D}(\mathrm{M})$ here $)$ is the partition coefficient between liquid metal and liquid silicate (Righter et al., 1997). For Earth 
479 calculations, $\mathrm{x}=0.68$, and $\mathrm{p}=0.6 ; D_{L M / L S}^{M o}$ is calculated using equation (8) and the regression 480 coefficients in Table S6, and $D_{S S / L S}^{M o}$ is $<<1$ for Mo (e.g., Sharp et al., 2015). $\operatorname{lnD}$ '(Mo) is 481 calculated first, and then converted to $\ln \mathrm{D}(\mathrm{Mo})$ with activity correction using metal compositions 482 of core forming metal used in accretion calculations described above.

484 are shown in Figure 8 compared to the values measured in the bulk silicate Earth (BSE). During 485 most of accretion, the mantle Mo contents stay low, but continuously increase due to pressure 486 effects and the increasing solubility of $\mathrm{Si}$ in the core forming Fe metal. In the "reduced to 487 oxidized" scenario, the increasing $\mathrm{fO}_{2}$ also causes $\mathrm{D}(\mathrm{Mo})$ to decrease and thus the Mo 488 concentration in the mantle to increase during accretion. These calculations show that the 489 concentration of the moderately siderophile element Mo can be explained by a rather simple 490 scenario of continuous accretion leading to a high PT metal-silicate scenario that establishes the 491 Mo content of Earth's PUM near the end of accretion. These results are not strongly dependent 492 upon the $\mathrm{fO}_{2}$ during accretion, although the "reduced to oxidized" scenario modelled here allows 493 attainment of PUM levels of Mo at slightly lower pressures compared to the "constant $\mathrm{fO}_{2}$ " 494 scenario. Addition of oxygen to the modelling results in negligible differences because at these 495 PT conditions the amount of oxygen dissolved in metallic liquid is very small (Ricolleau et al., 496 2011), and the effect of $\mathrm{O}$ on the Mo activity coefficient is nearly zero $\left(\varepsilon_{M o}^{S i}=22\right.$ vs. $\varepsilon_{M o}^{O}=1.26$; 497 Steelmaking Sourcebook, 1988); the most important light element affecting the activity of Mo in 498 metallic liquids is $\mathrm{Si}$, as demonstrated here and by Tuff et al. (2011) and Ono-Nakazato et al. 499 (2007). 
A fundamental aspect of planet formation is large-scale late impacts. It is not clear if

502

503

504

505

506

507

508

509

510

511

512

513

514

515

516

517

518

519 520 the PUM.

521

522

523

there is chemical equilibrium in a late impact scenario and this question is currently under consideration. Our new results for Mo can be used to evaluate late impact scenarios involving full and partial equilibrium, using the approach of Dauphas et al. (2014). Considering an impactor and proto-Earth merging in a late collision can be modeled using the approach and equations (11) to (15) from Dauphas et al. (2014) in which a differentiated impactor (core and mantle) impacts a differentiated proto-Earth (core and mantle) with a mass ratio of 0.5 (impactor contribution to Earth's mantle) and core fractions of 0.3 in both. We set the Mo contents of the mantle of the impactor and proto-Earth at 12 and $18 \mathrm{ppb}$, respectively, and [Mo] in core of 3200 and $3000 \mathrm{ppb}$, respectively. This results in bulk Mo of $1000 \mathrm{ppb}$ for each body and $\mathrm{D}$ (metal/silicate) of 267 and 167 for the impactor and proto-Earth, respectively. If these bodies completely re-equilibrate, the resulting Earth mantle has a Mo content of 25.6 (Figure 9). This is very close to the value determined by Greber et al. (2015) or $23( \pm 7) \mathrm{ppb}$. If the mass ratio of 0.1 (impactor contribution to Earth's mantle) is used instead, the value changes slightly to $25.0 \mathrm{ppb}$. Similarly, if the mass fraction of impactor core equilibrating with Earth's mantle is 0.5 instead of 1 , the value is $25.4 \mathrm{ppb}$, not much different. If however, the degree of equilibration is lowered to $<0.05$, the value drops below $20 \mathrm{ppb}$. However, this value is much lower than any modeling currently predicts (Rubie et al., 2015) and so for scenarios of dis-equilibrium, the value in Earth's mantle is similar to that for equilibrium and overlaps with the measured Mo content of

Thus, producing the bulk Mo content does not necessarily require late (post-core formation) addition of chondritic materials, as some have argued for W isotopes, HSEs, and volatile elements (e.g., Touboul et al., 2015; Walker, 2009; Rose-Weston et al., 2008; Ballhaus et 
524 al., 2012). In fact, our results are consistent with the conclusions of Greber et al. (2015) who

525 argued that the similarity of Mo isotope composition $\left(\delta^{98} \mathrm{Mo}\right)$ between Earth's PUM and 526 chondritic meteorites (Hin et al., 2013) implies overall chemical and isotopic equilibrium 527 between core and mantle.

528 Conclusions

New XANES measurements of Mo valence at high PT conditions and FeO bearing 530 silicate melts show that Mo4+ is stable at high PT and below IW-1 and thus at the conditions of 531 terrestrial core formation. Pressure has a slight but important effect on Mo partitioning causing a 532 reduction at higher pressures; our new data double the number of experimental determination at 533 pressures $>10 \mathrm{GPa}$. Si alloyed in Fe metallic liquids causes a lower $\mathrm{D}(\mathrm{Mo})$ metal-silicate, with 534 the most significant effect in C-bearing metallic liquids. Combination of our new data with 535 previous experimental studies allows derivation of predictive expression for $\mathrm{D}(\mathrm{Mo})$ 536 metal/silicate. Using our XANES results as a guide we utilize only experiments at IW-1 or lower 537 where $\mathrm{Mo}^{4+}$ is stable. Using this new expression, we show that the Mo content of Earth's 538 primitive upper mantle can be explained by chemical and (isotopic) equilibrium between core539 forming metallic liquid and molten mantle in a deep magma ocean scenario (35 to $45 \mathrm{GPa}$ ). 540 Future efforts should focus on obtaining partitioning data at pressures $>20 \mathrm{GPa}$.

542 Acknowledgements

543 Roger Harrington provided beautiful thin sections of several experimental run products. 544 Portions of this work were performed at GeoSoilEnviroCARS (Sector 13), Advanced Photon 
545 Source (APS), Argonne National Laboratory. GeoSoilEnviroCARS is supported by the National 546 Science Foundation - Earth Sciences (EAR-1128799) and Department of Energy- GeoSciences 547 (DE-FG02-94ER14466). This research used resources of the Advanced Photon Source, a U.S. 548 Department of Energy (DOE) Office of Science User Facility operated for the DOE Office of 549 Science by Argonne National Laboratory under Contract No. DE-AC02-06CH11357. Research 550 was also supported by an RTOP to KR from the NASA Cosmochemistry Program. We thank 551 Nicolas Dauphas and 3 anonymous reviewers for comments that helped improve the manuscript. 


\section{References}

Agrinier, A., Lee, C.-T., 2007. Quantifying trace element disequilibria in mantle xenoliths and abyssal peridotite. Earth Planet. Sci. Lett. 257, 290-298.

Andrault, D., Bolfan-Casanova, N., Lo Nigro, G., Bouhifd, M.A., Garbarino, G., Mezouar, M., 2011. Solidus and liquidus profiles of chondritic mantle: Implication for melting of the Earth across its history. Earth Planet. Sci. Lett. 304, 251-259.

Armytage, R.M.G., Georg, R.B., Savage, P.S., Williams, H.M., Halliday, A.N., 2011. Silicon isotopes in meteorites and planetary core formation. Geochim. Cosmochim. Acta 75, 36623676.

Badro, J., Brodholt, J. P., Piet, H., Siebert, J., \& Ryerson, F. J. 2015. Core formation and core composition from coupled geochemical and geophysical constraints. Proc. Nat. Acad. Sci. $112,12310-12314$.

Ballhaus, C., Laurenz, V., Münker, C., Fonseca, R.O., Albarède, F., Rohrbach, A. Helmy, H.M., 2013. The U/Pb ratio of the Earth's mantle - A signature of late volatile addition. Earth Planet. Sci. Lett. 362, 237-245.

Berry, A.J., O’Neill, H.St.C., 2004. A XANES determination of the oxidation state of chromium in silicate glasses. American Mineralogist 89, 790-798.

Berthet, S., Malavergne, V., and Righter, K., 2009. Evolution of Indarch (EH4 chondrite) at 1 GPa and high temperature: implications for early planetary differentiation processes. Geochim. Cosmochim. Acta 73, 6402-6420.

Boujibar, A., Andrault, D., Bouhifd, M.A., Bolfan-Casanova, N., Devidal, J.L., Trcera, N., 2014. Metal-silicate partitioning of sulphur, new experimental and thermodynamic constraints on planetary accretion. Earth Planet. Sci. Lett. 391, 42-54. 
577 Campbell, A.J., Danielson, L., Righter, K., Seagle, C.T., Wang, Y., Prakapenka, V.B., 2009.

578 High pressure effects on the iron-iron oxide and nickel-nickel oxide oxygen fugacity 579 buffers. Earth Planet. Sci. Lett. 286, 556-564.

580 Chakrabarti, R., Jacobsen, S.B., 2010. Silicon isotopes in the inner Solar System: Implications 581 for core formation, solar nebular processes and partial melting. Geochim. Cosmochim. Acta $582 \quad 74,6921-6933$.

583 Chi, H., Dasgupta, R., Duncan, M. S., Shimizu, N., 2014. Partitioning of carbon between Fe-rich

Cottrell, E., Walter, M. J., \& Walker, D. 2009. Metal-silicate partitioning of tungsten at high alloy melt and silicate melt in a magma ocean-Implications for the abundance and origin of volatiles in Earth, Mars, and the Moon. Geochim. Cosmochim. Acta 139, 447-471. pressure and temperature: implications for equilibrium core formation in Earth. Earth Planet. Sci. Lett. 281, 275-287.

Dasgupta, R., Chi, H., Shimizu, N., Buono, A. S., Walker, D., 2013. Carbon solution and partitioning between metallic and silicate melts in a shallow magma ocean: implications for the origin and distribution of terrestrial carbon. Geochim. Cosmochim. Acta 102, 191-212.

Dauphas, N., Poitrasson, F., Burkhardt, C., Kobayashi, H., \& Kurosawa, K. 2015. Planetary and meteoritic $\mathrm{Mg} / \mathrm{Si}$ and $\delta 30 \mathrm{Si}$ variations inherited from solar nebula chemistry. Earth Planet. Sci. Lett. 427, 236-248.

Dauphas, N., Burkhardt, C., Warren, P. H., Fang-Zhen, T., 2014. Geochemical arguments for an Earth-like Moon-forming impactor. Phil. Trans. Roy. Soc. Lon. A: Math., Phys. Eng. Sci, $372,20130244$.

Deguen, R., Landeau, M., Olson, P., 2014. Turbulent metal-silicate mixing, fragmentation, and equilibration in magma oceans. Earth Planet. Sci. Lett. 391, 274-287. 
600

601

602

603

604

605

606

607

608

609

610

611

612

613

614

615

616

617

618

619

620

Farges F., Siewert R., Brown G.E. Jr., Guesdon A. Morin G., 2006. Structural environments around molybdenum in silicate glasses and melts. I. influence of composition and oxygen fugacity on the local structure of molybdenum. Canadian Mineralogist 44, 731-753.

Farges F., Siewert R., Ponader C.W., Brown G.E. Jr., Pichavant M., Behrens H., 2006. Structural environments around molybdenum in silicate glasses and melts. II. Effect of temperature, pressure, $\mathrm{H}_{2} \mathrm{O}$, halogens and sulfur. Canadian Mineralogist 44, 755-773.

Filiberto, J., Treiman, A.H., Le, L., 2008. Crystallization Experiments on a Gusev Basalt Composition. Met. Planet. Sci. 43, 1137-1146.

Fitoussi, C., Bourdon, B., Kleine, T., Oberli, F., Reynolds, B. C., 2009. Si isotope systematics of meteorites and terrestrial peridotites: implications for $\mathrm{Mg} / \mathrm{Si}$ fractionation in the solar nebula and for Si in the Earth's core. Earth Planet. Sci. Lett. 287, 77-85.

Gao, S., Liu, X., Yuan, H., Hattendorf, B., Günther, D., Chen, L., Hu, S., 2002. Determination of forty two major and trace elements in USGS and NIST SRM glasses by laser ablation-inductively coupled plasma-mass spectrometry. Geost. Newsl. 26, 181-196.

Georg, R.B., Halliday, A.N., Schauble, E.A., Reynolds, B.C., 2007. Silicon in the Earth's core. Nature 447, 1102-1106.

Greber, N.D., Puchtel, I.S., Nägler, T.F., Mezger, K., 2015. Komatiites constrain molybdenum isotope composition of the Earth's mantle. Earth Planet. Sci. Lett. 421, 129-138.

Hillgren, V.J., Drake, M.J., Rubie, D.C., 1996. High-pressure and high-temperature metalsilicate partitioning of siderophile elements: the importance of silicate liquid composition. Geochim. Cosmochim. Acta 60, 2257 - 2263. 
621 Hillgren, V.J., Gessmann, C.K., Li, J., 2000. An experimental perspective on the light element in 622 Earth's core. In Origin of the Earth and Moon, eds. R. Canup and K. Righter, 245-263, Univ. 623 Arizona Press, Tucson, Arizona.

624 Hin, R.C., Burkhardt, C., Schmidt, M.W., Bourdon, B., Kleine, T., 2013. Experimental evidence 625 for Mo isotope fractionation between metal and silicate liquids. Earth Planet. Sci. Lett. 379, $626 \quad 38-48$

627 Holzheid, A., Palme, H., 2007. The formation of eucrites: Constraints from metal-silicate 628 partition coefficients. Met. Planet. Sci. 42, 1817-1829.

629 Holzheid, A., Borisov, A., Palme, H., 1994. The effect of oxygen fugacity and temperature on 630 solubilities of nickel, cobalt, and molybdenum in silicate melts Geochim. Cosmochim. Acta $631 \quad 58,1975-1981$.

632 Holzheid, A., Palme, H., Chakraborty, S., 1997. The activities of NiO, CoO and FeO in silicate 633 melts. Chemical Geology 139, 21-38.

634 Jana, D., Walker, D., 1997a. The influence of silicate melt composition on distribution of 635 siderophile elements among metal and silicate liquids. Earth Planet. Sci. Lett. 150, 463-72.

636 Jana, D. Walker, D., 1997b. The influence of sulfur on partitioning of siderophile elements. 637 Geochim. Cosmochim. Acta 61, 5255-77.

638 Kegler, P., Holzheid, A., Frost, D. J., Rubie, D. C., Dohmen, R., \& Palme, H. (2008). New Ni 639 and Co metal-silicate partitioning data and their relevance for an early terrestrial magma $640 \quad$ ocean. Earth Planet. Sci. Lett. 268, 28-40.

641 Kendall, J., Melosh, H.J., 2014. Dispersion of Planetesimal Iron Cores During Accretional $642 \quad$ Impacts. Lunar and Planetary Science Conference 45, p. 2827. 
643 Lewis, R.D., Lofgren, G.E., Franzen, H.F., Windom, K.E., 1993. The effect of Na vapor on the $644 \quad$ Na content of chondrules. Meteoritics 28, 622-628.

645 Ma, Z., 2001. Thermodynamic description for concentrated metallic solutions using interaction 646 parameters. Metall. Mat. Trans. B 32, 87-103.

647 Malavergne, V., Charon, E., Jones, J., Cordier, P., Righter, K., Deldicque, D., and L. Hennet 648 (2016) The formation of nuggets of highly siderophile elements in quenched silicate melts at 649 high temperatures: before or during the silicate quench? Earth Planet. Sci. Lett., in press.

650 McDonough, W.F., 2003. Compositional model for the Earth's core. Treatise on geochemistry, 2, $651 \quad 547-568$.

652 Newsom, H.E., 1995. In AGU Reference Shelf 1. Global Earth Physics: A Handbook of Physical $653 \quad$ Constants, 159-189.

654 O'Neill, H.St.C, Eggins, S.M., 2002. The effect of melt composition on trace element 655 partitioning: an experimental investigation of the activity coefficients of $\mathrm{FeO}, \mathrm{NiO}, \mathrm{CoO}$, $656 \quad \mathrm{MoO}_{2}$ and $\mathrm{MoO}_{3}$ in silicate melts. Chem. Geol. 186, 151-181.

657 Ono-Nakazato, H., Taguchi, K., Maruo, R, Usui, T., 2007. Silicon deoxidation equilibrium of 658 molten Fe-Mo alloy. ISIJ International 47, 365-369.

659 Poe, B.T., C. Romano, N. Zotov, G. Cibin, A. Marcelli, 2001. Compression mechanisms in 660 aluminosilicate melts: Raman and XANES spectroscopy of glasses quenched from pressures 661 up to $10 \mathrm{GPa}$, Chemical Geology $174,21-31$.

662 Ravel. B., Newville. M., 2005. ATHENA, ARTEMIS, HEPHAESTUS: data analysis for X-ray 663 absorption spectroscopy using IFEFFIT. Jour. Synch. Rad. 12, 537-541. 
664 Ricolleau, A., Fei, Y., Corgne, A., Siebert, J., Badro, J., 2011. Oxygen and silicon contents of 665 Earth's core from high pressure metal-silicate partitioning experiments. Earth Planet. Sci. $666 \quad$ Lett. $310,409-421$.

667 Righter, K. 2011. Prediction of metal-silicate partition coefficients for siderophile elements: An 668 update and assessment of PT conditions for metal-silicate equilibrium during accretion of the Earth. Earth Planet. Sci. Lett. 304, 158-167.

670 Righter, K., Drake, M.J., 1999. Effect of water on metal-silicate partitioning of siderophile elements: a high pressure and temperature terrestrial magma ocean and core formation. Earth Planet. Sci. Lett. 171, 383-399.

673 Righter, K., Ghiorso, M.S., 2012. Redox systematics of a magma ocean with variable pressure674 temperature gradients and composition. Proc. Nat. Acad. Sci. 109, 11955-11960.

675 Righter, K. Drake, M.J., Yaxley, G., 1997. Prediction of siderophile element metal - silicate 676 partition coefficients to $20 \mathrm{GPa}$ and $2800{ }^{\circ} \mathrm{C}$ : the effect of pressure, temperature, $\mathrm{fO}_{2}$ and 677 silicate and metallic melt composition, Phys. Earth Planet. Int. 100, 115-134.

678 Righter, K., Hervig, R.L., Kring, D., 1998. Accretion and core formation in Mars: Molybdenum 679 contents of melt inclusion glasses from three SNC meteorites. Geochim. Cosmochim. Acta 680 $62,2167-2177$.

Righter, K., Sutton, S.R., Newville, M., Le, L., Schwandt, C.S., Uchida, H., Lavina, B., Downs, 682 R.T., 2006. Oxidation state of vanadium in spinel and silicate melt: implications for planetary basalts and mantle melting. American Mineralogist 91, 1643-1656.

Righter, K., Humayun, M., Danielson, L.R., 2008. High pressure and temperature partitioning of 685 palladium during core formation. Nature Geoscience 1, 321-323. 
Righter, K., Pando, K., Danielson, L.R., Lee, C.-T., 2010. Partitioning of Mo, P and other siderophile elements $(\mathrm{Cu}, \mathrm{Ga}, \mathrm{Sn}, \mathrm{Ni}, \mathrm{Co}, \mathrm{Cr}, \mathrm{Mn}, \mathrm{V}, \mathrm{W})$ between metal and silicate melt as a function of temperature and melt composition. Earth Planet. Sci. Lett. 291, 1-9.

Righter, K., Danielson, L.R., Pando, K., Morris, R.V., Graff, T.G., Agresti, D.G., Martin, A.M., Sutton, S.R., Newville, M., Lanzirotti, A. 2013. Redox systematics of martian magmas with implications for magnetite stability. Amer. Mineral 98, 616-628.

Rose-Weston, L., Brenan, J. M., Fei, Y., Secco, R. A., Frost, D. J., 2009. Effect of pressure, temperature, and oxygen fugacity on the metal-silicate partitioning of $\mathrm{Te}, \mathrm{Se}$, and $\mathrm{S}$ : Implications for earth differentiation. Geochim. Cosmochim. Acta 73, 4598-4615.

Rubie, D.C., Frost, D.J., Mann, U., Asahara, Y., Nimmo, F., Tsuno, K., Kegler, P., Holzheid, A., Palme, H., 2011. Heterogeneous accretion, composition and core-mantle differentiation of the Earth. Earth Planet. Sci. Lett. 301, 31 - 42.

Rubie, D.C., Jacobson, S.A., Morbidelli, A., O’Brien, D.P., Young, E.D., de Vries, J., Frost, D.J., 2015. Accretion and differentiation of the terrestrial planets with implications for the compositions of early-formed Solar System bodies and accretion of water. Icarus 248, 89108.

Rudnick, R.L., Gao, S., Ling, W., Liu, Y., McDonough, W.F., 2004. Petrology and geochemistry of spinel peridotite xenoliths from the Hannuoba and Qixia, North China craton. Lithos 77, $609-637$.

Sanloup, C., Drewitt, J.W., Konôpková, Z., Dalladay-Simpson, P., Morton, D.M., Rai, N., Morgenroth, W., 2013. Structural change in molten basalt at deep mantle conditions. Nature 503, 104-107. 
Savage, P.S., Moynier, F., 2013. Silicon isotopic variation in enstatite meteorites: clues to their origin and Earth-forming material. Earth Planet. Sci. Lett. 361, 487-496.

Shahar, A., Ziegler, K., Young, E.D., Ricolleau, A., Schauble, E.A., Fei, Y., 2009. Experimentally determined $\mathrm{Si}$ isotope fractionation between silicate and $\mathrm{Fe}$ metal and implications for Earth's core formation. Earth Planet. Sci. Lett. 288, 228-234.

Sharp, M., Righter, K., Walker, R.J., 2015. Estimation of trace element concentrations in the lunar magma ocean using mineral-and metal-silicate melt partition coefficients. Met. Planet. Sci. 50, 733-758.

Shofner, G.A., 2011. High Pressure Redox Geochemistry of Tungsten in Metal-Silicate Systems: Implications for Core Formation in the Earth. Ph.D. thesis, University of Maryland, 175 pp.

Shofner, G.A., Campbell, A.J., Danielson, L.R., Rahmen, Z., Righter, K., 2015. Metal-silicate partitioning of tungsten from 10 to $50 \mathrm{GPa}$ : implications for core formation. Geochim. Cosmochim. Acta, in preparation.

Siebert, J., Badro, J., Antonangeli, D., Ryerson, F.J., 2013. Terrestrial accretion under oxidizing conditions. Science 339, 1194-1197.

Siebert, J., Corgne, A., Ryerson, F.J., 2011. Systematics of metal-silicate partitioning for many siderophile elements applied to Earth's core formation. Geochim. Cosmochim. Acta 75, $1451-1489$.

Steelmaking, J. 1988. Steelmaking Data Sourcebook. Gordon and Breach Science Publishers, Montreux.

Sutton, S.R., Bertsch, P.M., Newville, M., Rivers, M.L., Lanzirotti, A., Eng, P., 2002. Microfluoresence and microtomography analyses of heterogeneous earth and environmental 
materials (in Applications of synchrotron radiation in low-temperature geochemistry and environmental sciences). Rev. Mineral. Geochem. 49, 429-483.

732 Touboul, M., Puchtel, I.S., Walker, R.J., 2015. Tungsten isotopic evidence for disproportional 733 late accretion to the Earth and Moon. Nature 520, 530-533.

734 Tuff, J., Wood, B.J., Wade, J., 2011. The effect of Si on metal-silicate partitioning of siderophile 735 elements and implications for the conditions of core formation. Geochim. Cosmochim. Acta 736 75, 673-690.

737 Wade, J., Wood, B.J, 2001. The Earth's `missing' niobium may be in the core. Nature 409, 75-78. 738 Wade J., Wood B.J., 2005. Core formation and the oxidation state of the Earth. Earth Planet. Sci. $739 \quad$ Lett. 236, 78-95.

740 Wade, J., Wood, B.J, Tuff, J., 2012. Metal-silicate partitioning of Mo and W at high pressures 741 and temperatures: Evidence for late accretion of sulphur to the Earth. Geochim. Cosmochim. $742 \quad$ Acta 85, $57-74$.

743 Wagner, C., 1962. Thermodynamics of Alloys. Addison-Wesley, Reading, MA.

744 Walker, R.J., 2009. Highly siderophile elements in the Earth, Moon and Mars: update and 745 implications for planetary accretion and differentiation. Chemie Erde Geochem. 69, 101-125. 746 Walter M.J., Thibault, Y., 1995. Partitioning of Tungsten and Molybdenum between Metallic $747 \quad$ Liquid and Silicate Melt. Science 270, 1186-1189.

748 Wood B.J., Walter M.J., Wade J., 2006. Accretion of the Earth and segregation of its core. $749 \quad$ Nature 441, 825-833.

750 Wood, B.J., Kiseeva, E.S., Mirolo, F.J., 2014. Accretion and core formation: The effects of 751 sulfur on metal-silicate partition coefficients. Geochim. Cosmochim. Acta 145, 248-267. 
752 Ziegler, K., Young, E.D., Schauble, E.A., Wasson, J.T., 2010. Metal-silicate silicon isotope 753 fractionation in enstatite meteorites and constraints on Earth's core formation. Earth Planet. 754 Sci. Lett. 295, 487-496.

755 


\section{Figure captions}

757 Figure 1: Examples of typical textures from experimental run products. Top left: back-scattered 758 electron (BSE) image of experiment GN24 carried out in a multi-anvil apparatus at $16 \mathrm{GPa}$, $759 \quad 2140{ }^{\circ} \mathrm{C}$ with an $\mathrm{MgO}$ capsule. Top right: BSE image of experiment "cow 3" carried out in a 760 piston cylinder apparatus at $1.0 \mathrm{GPa}, 1600{ }^{\circ} \mathrm{C}$ with a graphite capsule. Bottom left: Plane761 polarized light image of experiment "cow B1" carried out at $1.0 \mathrm{GPa}, 1600{ }^{\circ} \mathrm{C}$, in graphite capsule at IW-2.5. Bottom right: Plane-polarized light image of 1 bar experiment "Mo-cow IW-0.5" used for Mo XANES measurements and containing 16.5 ppm Mo. Circular features in both bottom images are laser holes created during analysis - the laser ablation analysis was done on thick mounts before the thin sections were made.

766

767

Figure 2a: Mo K XANES spectra (normalized) for the standards used in the linear combination fitting for valence determinations. $\mathrm{Mo}^{6+}$ is the spectrum for the ankaramite $\mathrm{IW}+2$ glass. $\mathrm{Mo}^{4+}$ is the ankaramite IW-2 glass corrected for $17 \% \mathrm{Mo}^{6+}$ indicated by comparison with spectra for $\mathrm{MoO}_{2}$ and $\mathrm{MoO}_{3} \cdot \mathrm{Mo}^{0}$ is the measured spectrum for metal nuggets in the cow IW2.8 sample. Mo metal foil, shown for reference only, is an energy calibration foil (EXAFS Materials, Danville, CA) collected in transmission. Figure 2b: Mo K XANES spectrum for ankaramite IW+1 (black), the linear combination fit (blue) and the component fits for the three valence standards: $\mathrm{Mo}^{0}$ (red; $\left.0 \%\right), \mathrm{Mo}^{4+}$ (green; 0\%), and $\mathrm{Mo}^{6+}(\mathrm{cyan} ; 100 \%)$. The residual from the fit is shown in orange. The valence for the non-metal component was dominantly 6.0 (5.91 in Table 1). Figure 2c: Mo K XANES spectrum for ankaramite IW-1 (black), the linear combination fit (blue) and the component fits for the three valence standards: $\mathrm{Mo}^{0}$ (red; $\left.0 \%\right), \mathrm{Mo}^{4+}$ (green; 51\%), and $\mathrm{Mo}^{6+}$ (cyan; 49\%). The residual from the fit is shown in orange. The valence for the non-metal component was a nearly equal mixture 

(black), the linear combination fit (blue), and the component fits for the three valence standards: $\mathrm{Mo}^{0}(\mathrm{red} ; 27 \%), \mathrm{Mo}^{4+}$ (green; 68\%), and $\mathrm{Mo}^{6+}$ (cyan; 5\%). The residual from the fit is shown in orange. The valence for the non-metal component was dominantly 4.0 (4.2 in Table 1).

784

785

786

787

Figure 3: Top: Comparison of ankaramite and basalt series (1 bar) to those of Holzheid et al. (1994) and Farges et al. (2006) showing relatively narrow range where all studies, regardless of temperature or melt composition, undergo transition from $\mathrm{Mo}^{4+}$ to $\mathrm{Mo}^{6+}$. Bottom: Plot of non-metal valence versus relative $\mathrm{fO}_{2}(\Delta \mathrm{IW})$ for the low-pressure subset of samples from this study - shown are those at 1 bar and $1.0 \mathrm{GPa}$ only. The curve shows the expected (theoretical) width of the two electron transition $\mathrm{Mo}^{4+}=\mathrm{Mo}^{6+}+2 \mathrm{e}^{-}$centered on IW-0.5, which correlates well with our data in this $\mathrm{fO}_{2}$ range. The shape of the curve is determined by the stoichiometry of the redox reaction $\mathrm{Mo}^{4+} \mathrm{O}_{2}+1 / 2 \mathrm{O}_{2}=\mathrm{Mo}^{6+} \mathrm{O}_{3}$, and is a function of the power to which $\mathrm{fO}_{2}$ is raised $(-1 / 2)$, for a two electron reaction. The non-metal valence data points shown (filled circles) are for analyses with small metal flake components after correction for those components (see text).

Figure 4: Plot of non-metal valence versus temperature and pressure. High PT experimental results indicate that as temperature increases from 1500 to $1800{ }^{\circ} \mathrm{C}$, Mo valence decreases from 6 to 5, and then at the high temperatures of 2000 to $2200{ }^{\circ} \mathrm{C}$, a valence of 4 is dominant. At pressures between 12 and $24 \mathrm{GPa}$ and IW-1.5, Mo exhibits a valence of 4 . Between 1 and $4 \mathrm{GPa}$ and IW+0.5, Mo exhibits dominantly 6+ valence. Experiment Mo-2 is not plotted with this series because its spectrum looked similar to that of $\mathrm{MoO}_{2}$ and small $\mathrm{MoO}_{2}$ crystals were present in the glass in this experiment. 
Figure 5a: $\ln \mathrm{Kd}(\mathrm{Fe}-\mathrm{Mo})$ vs. Si content of the metallic liquid showing the decrease at higher $\mathrm{Si}$ contents. Figure 5b: $\ln \mathrm{K}_{\mathrm{d}}(\mathrm{Fe}-\mathrm{Mo}) / \gamma \mathrm{Fe}$ vs. $\ln \left(1-\mathrm{X}_{\mathrm{Si}}\right)$, the slope of which yields the interaction parameter $\varepsilon_{M o}^{S i}$. Plotted are three new experiments from this study, cow B1, C2, and D1, as well as one Si-free experiments from Righter et al. (2010) at the same temperature - all at $1600{ }^{\circ} \mathrm{C}$. For comparison are the results for Mo reported by Tuff et al. (2011) at 1650 ${ }^{\circ} \mathrm{C}, 1.5 \mathrm{GPa}$ in $\mathrm{MgO}$ capsules. The $\mathrm{C}$-undersaturated or $\mathrm{C}$-free experiments yield a lower value of $\varepsilon_{M o}^{S i}$ than those from the C-saturated series.

Figure 6: $\ln \mathrm{Kd}(\mathrm{Fe}-\mathrm{Mo})$ vs. pressure for our experiments compared to those of Wade et al. (2012) at 6 and $24 \mathrm{GPa}$, as well as Hillgren et al. (1996) at $10 \mathrm{GPa}$, and Siebert et al. (2011) at 15 and $19 \mathrm{GPa}$. None of the metallic liquids in these experiment contain Si. Shaded grey region is the standard error on the regression of 1 bar data.

Figure 7: Comparison of $\mathrm{Fe}, \mathrm{S}, \mathrm{C}$, and $\mathrm{Si}$ content of the core-forming metallic $\mathrm{Fe}$ liquid as accretion proceeds for two different $\mathrm{fO}_{2}$ paths during accretion: a) one which starts reduced (IW-4) and finishes more oxidized (IW-2), and b) one which is relatively constant (IW-2). Pressure is along an adiabat as described in the text, and the S, C, and Si contents of the metallic liquid are calculated according to Boujibar et al. (2014), Chi et al. (2013), and Ricolleau et al. (2011).

Figure 8a: Calculations of mantle Mo content as Earth grows during accretion, for two different $\mathrm{fO}_{2}$ paths. Open circles indicate a scenario with $\mathrm{fO}_{2}$ staying relatively constant during accretion, whereas closed symbols indicate a second scenario where $\mathrm{fO}_{2}$ increases from IW-4 to IW-2 during accretion, with the metallic liquids changing in composition as indicated in Figure 7. Figure 8b: Calculated D(Mo) metal/silicate during accretion for increasing $\mathrm{fO}_{2}$, and constant relative $\mathrm{fO}_{2}$, as described for Fig. 8a and in the text. Mo content of the mantle is 
825 calculated using Equations (8) and (9). Shaded box shows the Mo content estimated for 826 Earth's primitive upper mantle and the required range of $\mathrm{D}(\mathrm{Mo})$ to explain Mo content of the 827 PUM (from Greber et al., 2015). All calculations are along the peridotite liquidus defined by 828 Andrault et al. (2011). Error on D(Mo) and Mo content is propagated from the error on the 829 regression from Table S6.

830 Figure 9: Mo content of the Earth's mantle calculated for a giant impact involving the impactor 831 and proto-Earth. Solid circles show an example where the mass fraction of the impactor in 832 Earth's mantle is 0.12 , and the open circles are where the mass fraction of the impactor in 833 Earth's mantle is 0.5 . X-axis shows the mass fraction of the impactor core that equilibrates 834 with Earth's mantle. Calculations utilize equations (11) to (15) from Dauphas et al. (2014) as 835 explained in the text. 
Figure 1
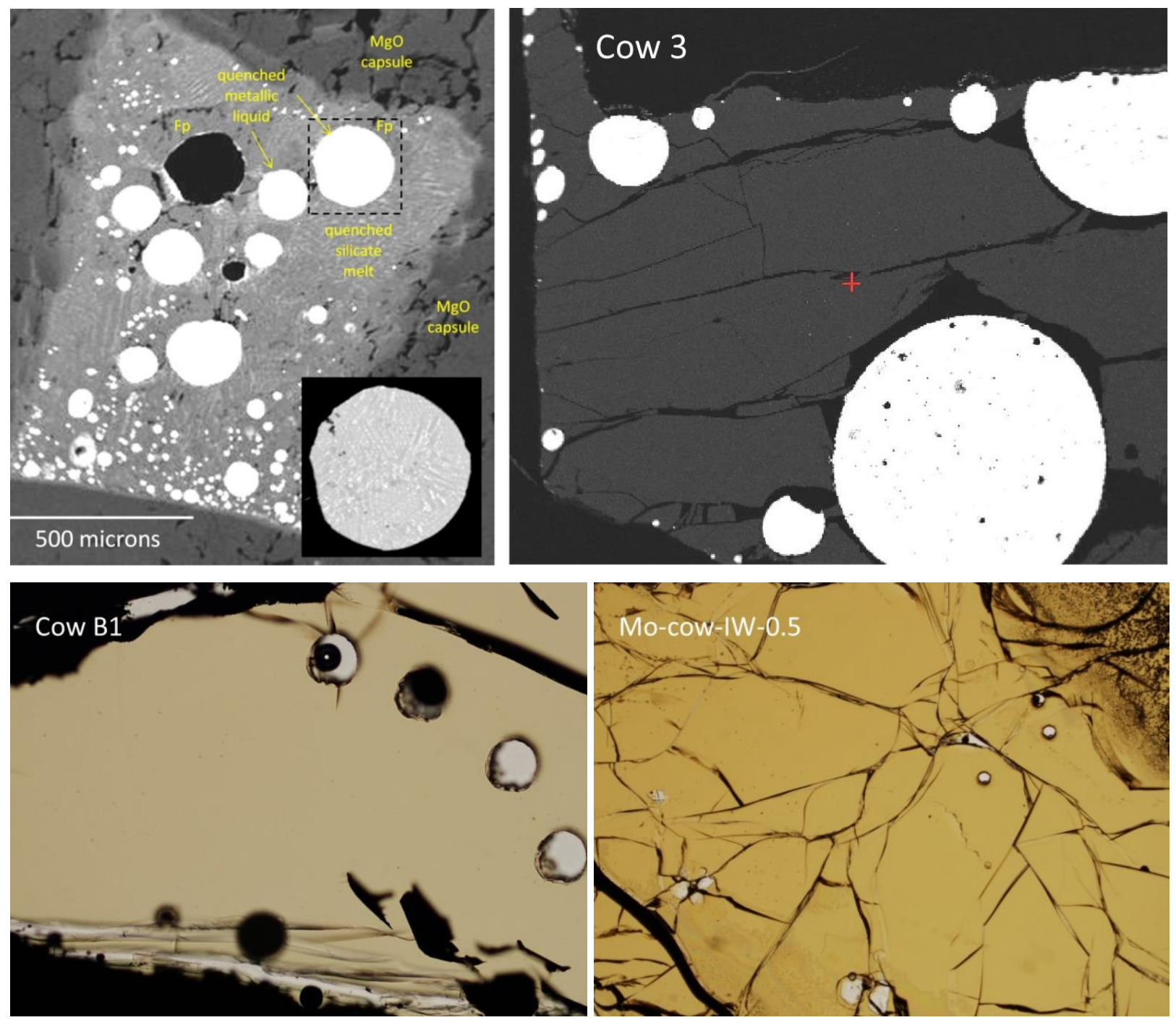
Figure 2
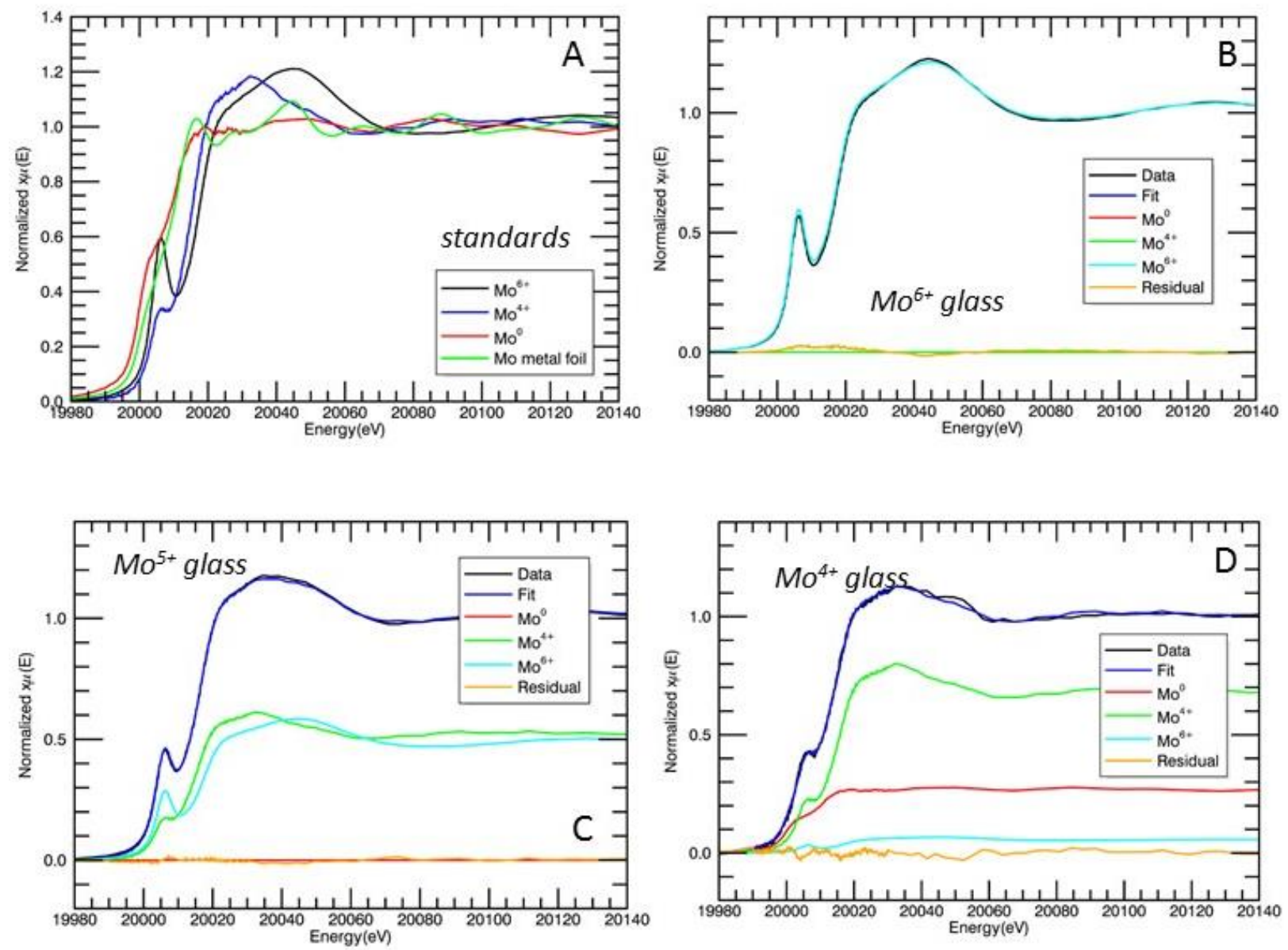
Figure 3
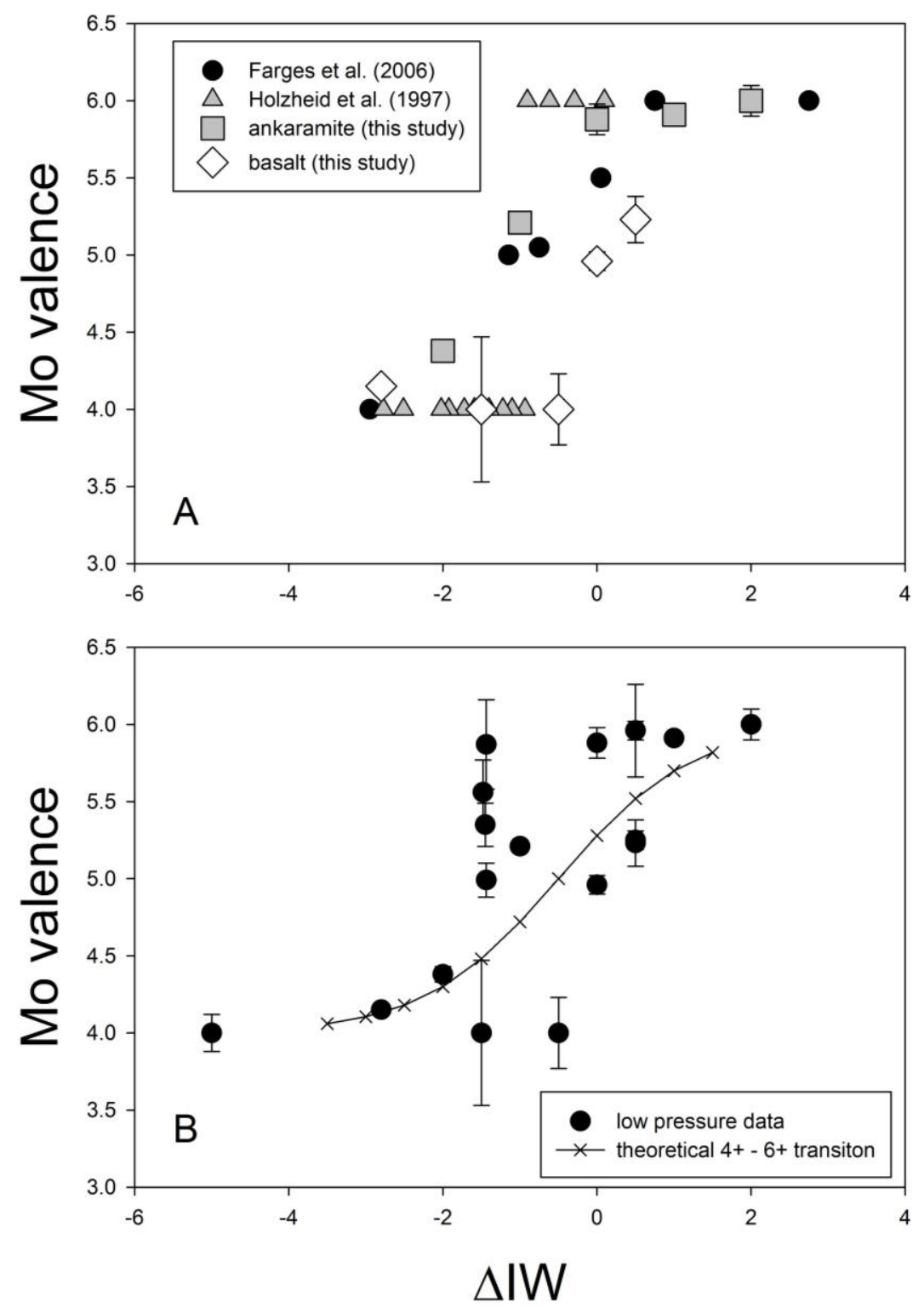
Figure 4
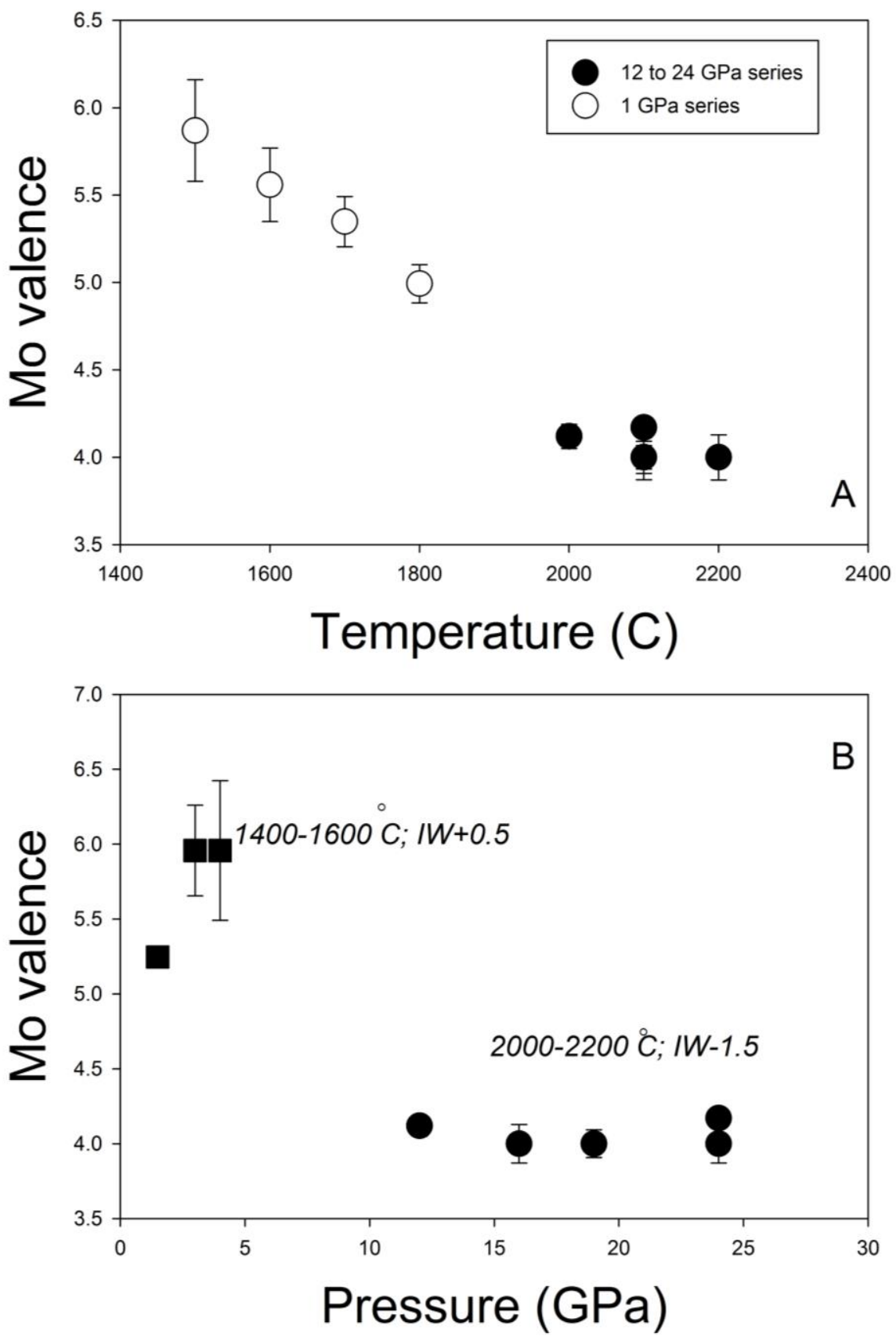
Figure 5

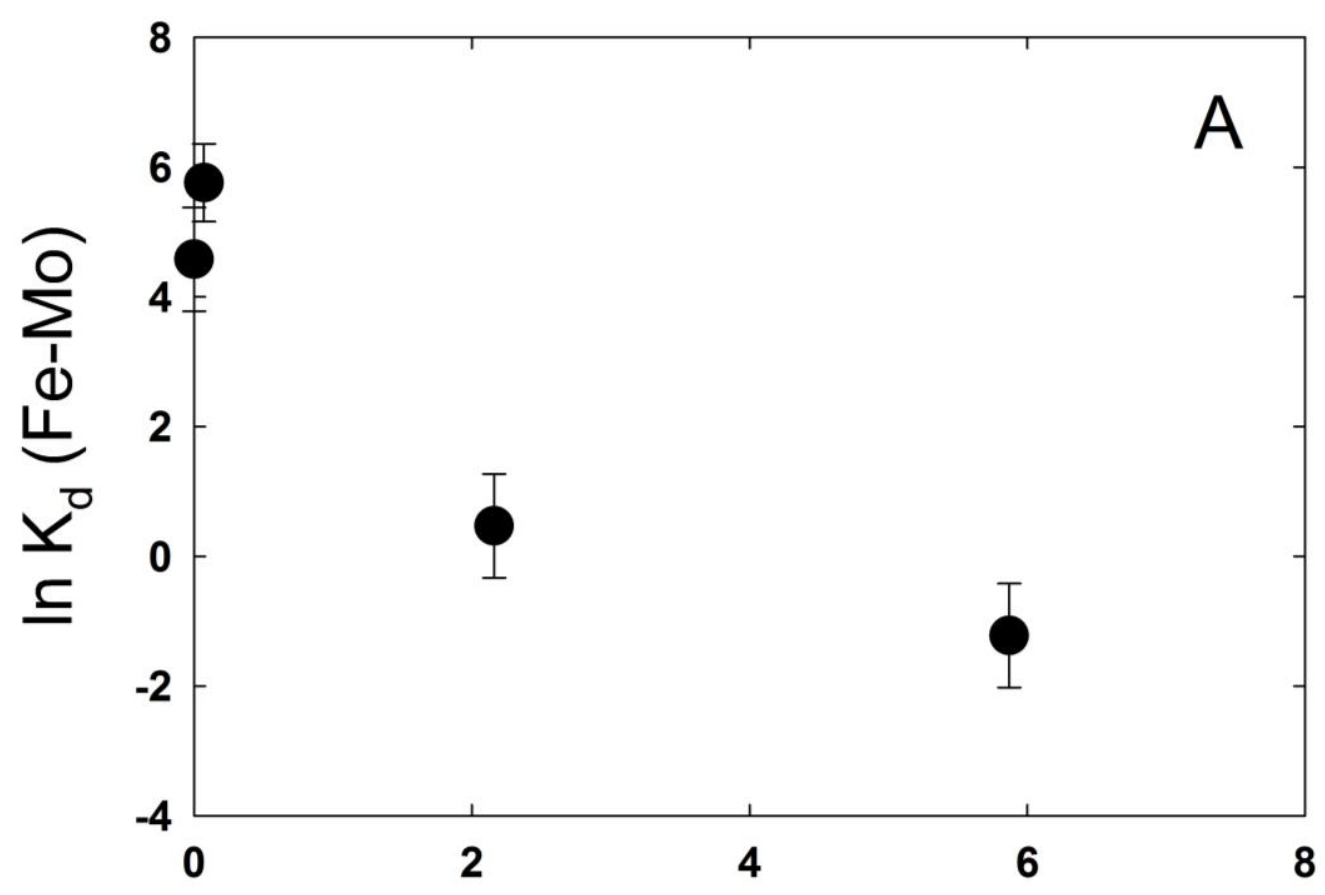

$\mathrm{Si}$ in Fe metallic liquid (wt\%)

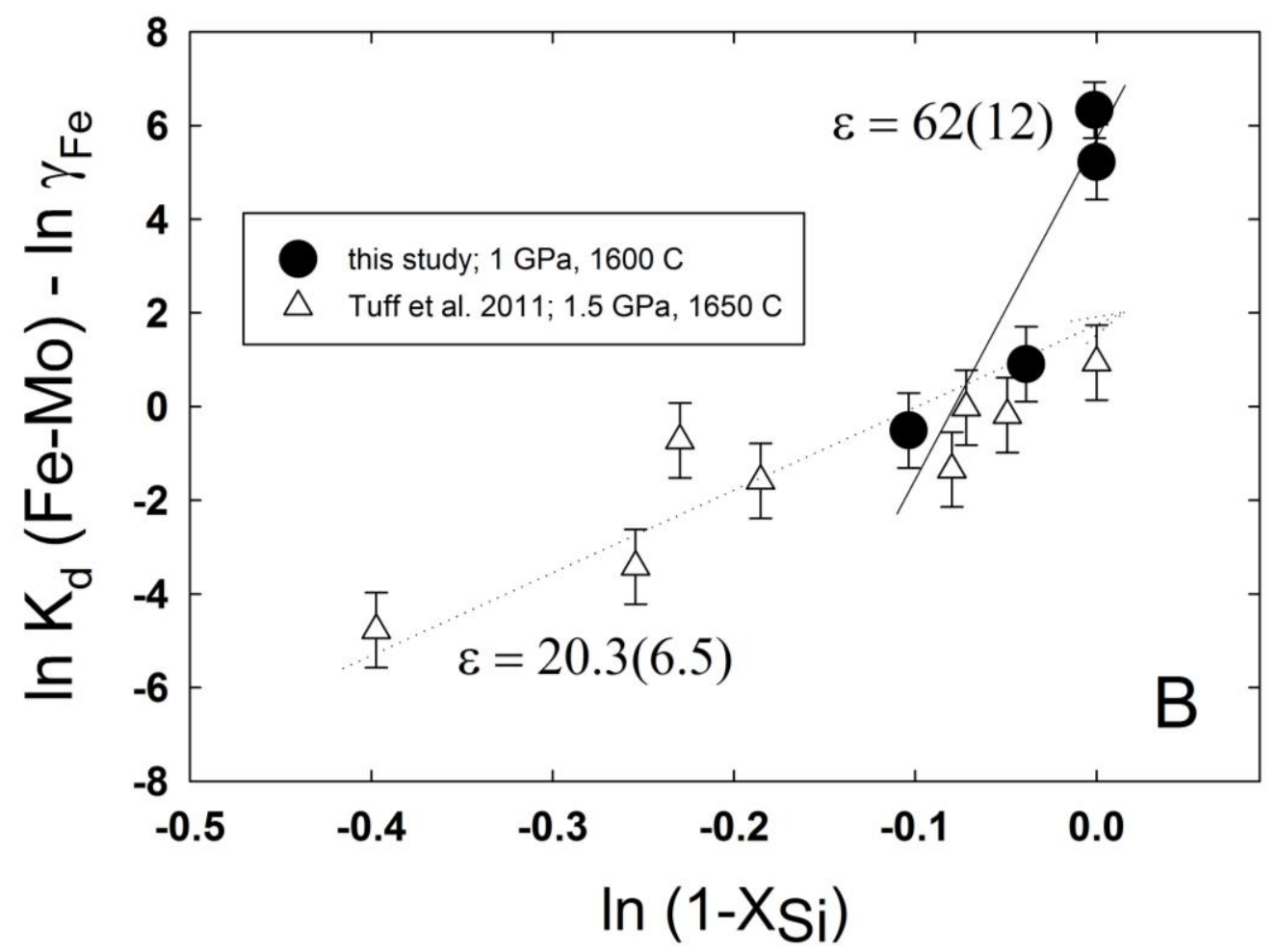


Figure 6

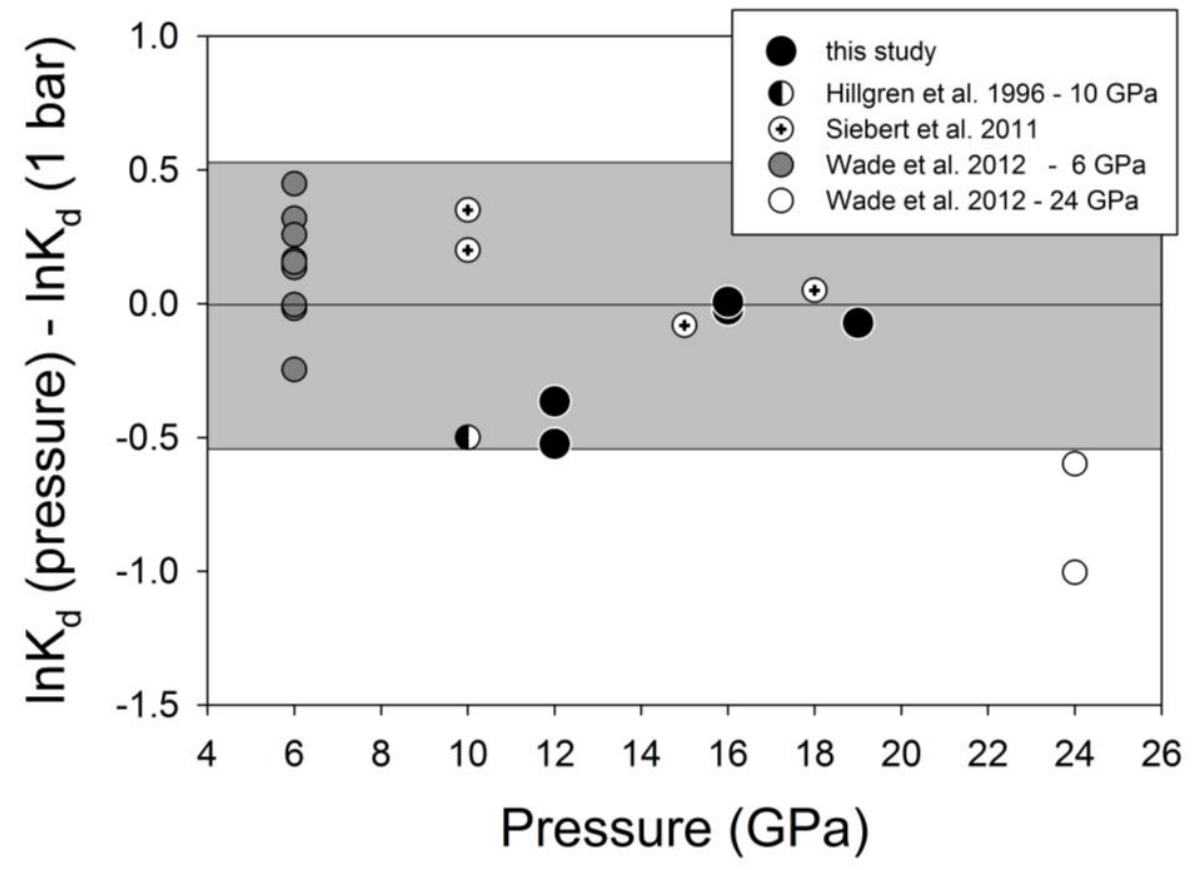


Figure 7
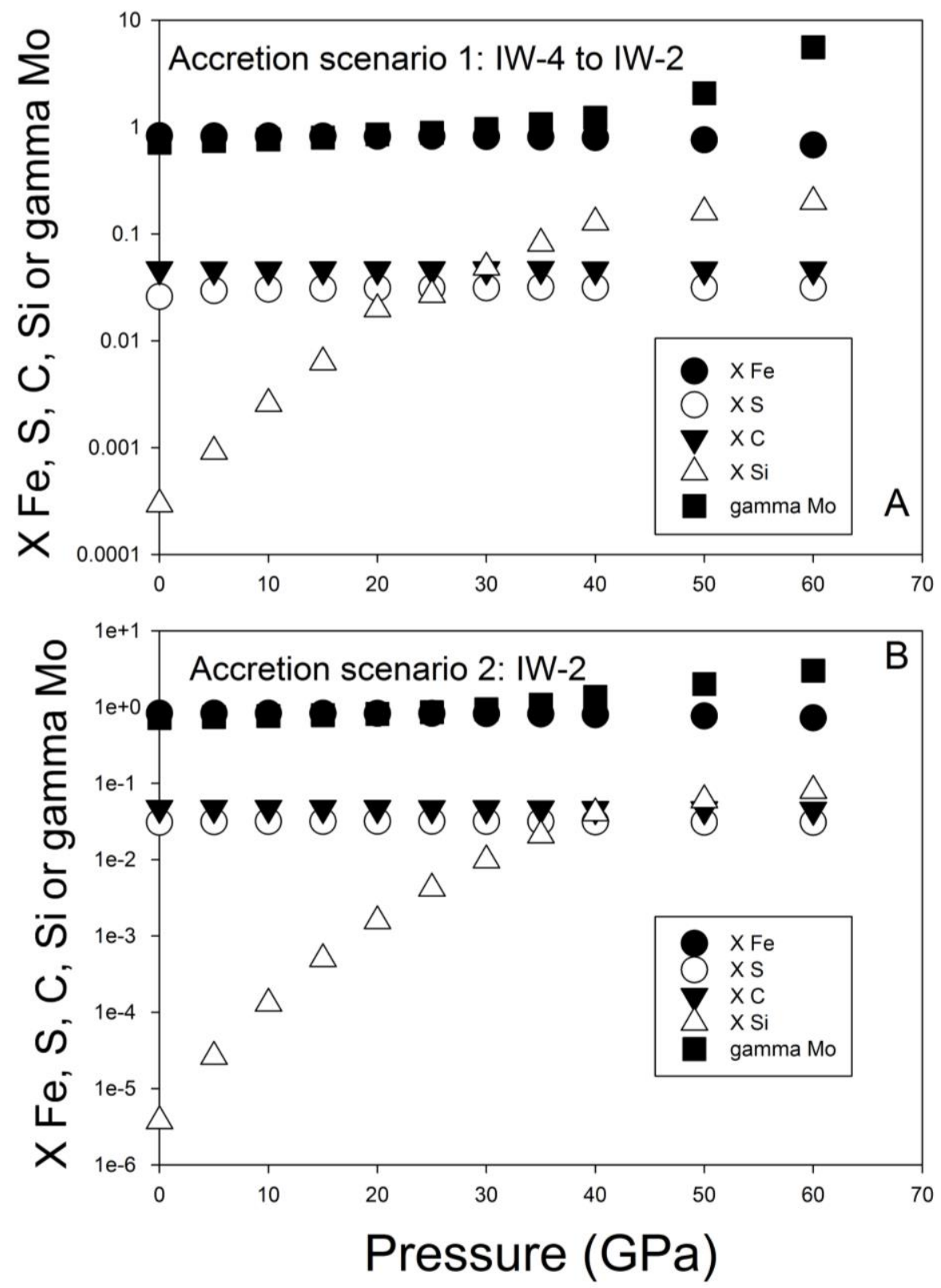
Figure 8
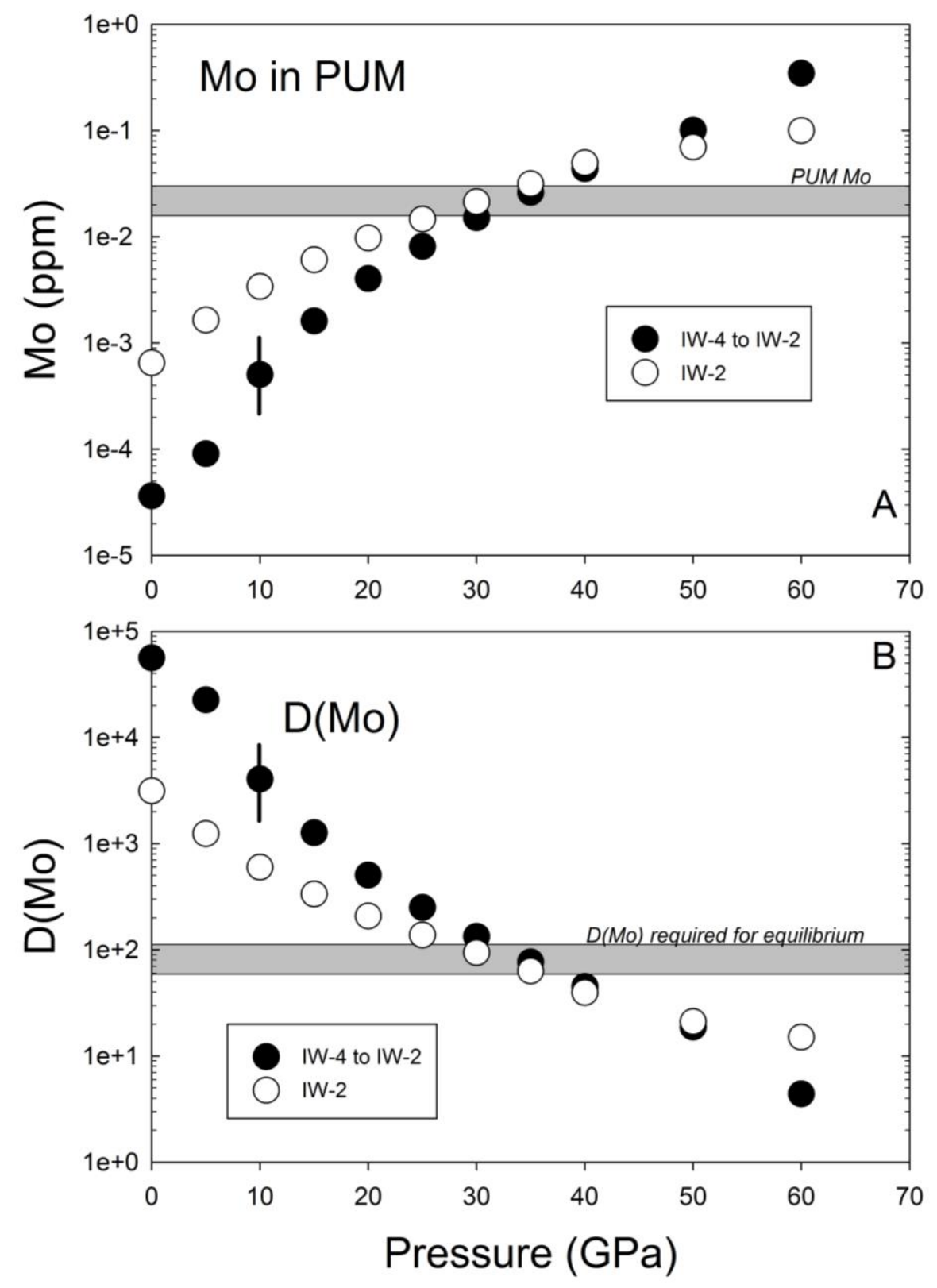
Figure 9

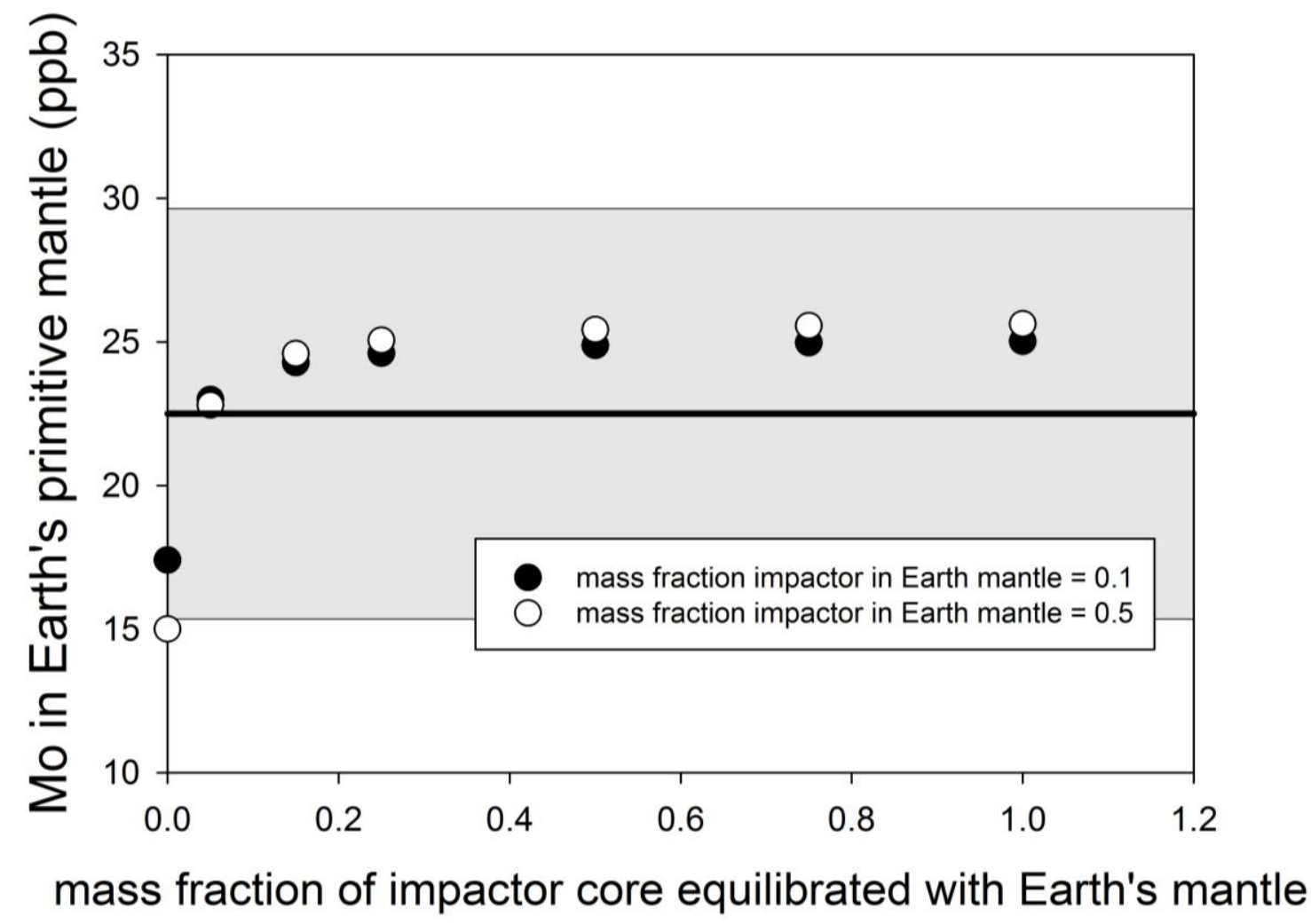


Table 1: XANES measurements from experimental samples

\begin{tabular}{|c|c|c|c|c|c|c|c|c|c|c|}
\hline Sample\# & $\Delta \mathbf{I W}$ & $\begin{array}{l}\text { Pressure } \\
\text { (GPa) }\end{array}$ & $\begin{array}{l}\text { Mo } \\
\text { (ppm) }\end{array}$ & $\begin{array}{l}\text { Temp } \\
\left({ }^{\circ} \mathrm{C}\right)\end{array}$ & $\mathbf{M o}^{6}$ & $\mathrm{Mo}^{4}$ & $\mathbf{M o}^{\mathbf{0 a}}$ & $\mathbf{M o}^{\mathbf{0 b}}$ & $\begin{array}{l}\text { Effective } \\
\text { Valence }\end{array}$ & $\begin{array}{l}\text { Non- } \\
\text { metal } \\
\text { valence }\end{array}$ \\
\hline cow B1 & -2.5 & 1.0 & 0.155 & 1600 & $0.000(67)$ & $0.278(75)$ & $0.722(33)$ & - & $1.11(50)$ & $4.00(47)$ \\
\hline cow D1 & -5 & 1.0 & 0.5 & 1600 & $0.000(25)$ & $0.499(29)$ & $0.501(12)$ & - & $2.00(19)$ & $4.00(10)$ \\
\hline cow1t & -1.44 & 1.0 & 2.9 & 1500 & $0.320(33)$ & $0.015(52)$ & $0.712(119)$ & $0.063(82)$ & $2.64(31)$ & $5.87(29)$ \\
\hline cow $3 t$ & -1.48 & 1.0 & 4.2 & 1600 & $0.419(47)$ & $0.107(70)$ & $0.457(161)$ & $0.000(114)$ & $3.36(42)$ & $5.56(21)$ \\
\hline cow8t & -1.45 & 1.0 & 4.9 & 1700 & $0.536(56)$ & $0.242(79)$ & $0.271(176)$ & $0.000(132)$ & $4.42(49)$ & $5.35(14)$ \\
\hline cow $20 \%$ & -1.44 & 1.0 & 6 & 1800 & $0.271(30)$ & $0.263(51)$ & $0.443(73)$ & $0.000(43)$ & $3.08(28)$ & $4.99(11)$ \\
\hline $66 \S$ & -0.72 & 1.0 & 11.78 & 1300 & $0.325(25)$ & $0.247(38)$ & $0.378(87)$ & $0.091(60)$ & $3.28(23)$ & $5.11(08)$ \\
\hline $67 \S$ & -0.84 & 1.0 & 0.49 & 1300 & $0.184(71)$ & $0.000(82)$ & $0.445(169)$ & $0.403(139)$ & $1.51(56)$ & $5.96(87)$ \\
\hline $68 \S$ & -0.72 & 1.0 & 0.91 & 1300 & $0.232(19)$ & $0.370(26)$ & $0.362(57)$ & $0.077(43)$ & $3.20(16)$ & $4.75(5)$ \\
\hline $74 \S$ & -0.70 & 1.0 & 3.74 & 1300 & $0.101(119)$ & $0.169(124)$ & $0.369(238)$ & $0.365(185)$ & $1.62(89)$ & $4.73(64)$ \\
\hline $76 \S$ & -0.69 & 1.0 & 4.79 & 1300 & $0.158(22)$ & $0.000(32)$ & $0.556(73)$ & $0.320(53)$ & $1.46(20)$ & $5.96(40)$ \\
\hline $80 \S$ & -0.66 & 1.0 & 8.23 & 1300 & $0.119(25)$ & $0.000(41)$ & $0.453(95)$ & $0.500(62)$ & $1.13(24)$ & $5.96(67)$ \\
\hline $83 \S$ & -0.63 & 1.0 & 4.61 & 1300 & $0.456(15)$ & $0.204(23)$ & $0.348(53)$ & $0.019(35)$ & $3.86(14)$ & $5.35(5)$ \\
\hline $87 \S$ & -0.68 & 1.0 & 0.11 & 1300 & $0.190(25)$ & $0.000(41)$ & $0.506(93)$ & $0.317(63)$ & $1.61(24)$ & $5.96(42)$ \\
\hline BJJB 126 & -1 & 16.0 & 108.3 & 2100 & $0.000(19)$ & $0.553(27)$ & $0.483(63)$ & $0.023(45)$ & $2.67(17)$ & $4.00(7)$ \\
\hline BJJB 127 & -1 & 16.0 & $\sim 100$ & 2100 & $0.000(17)$ & $0.259(25)$ & $0.538(59)$ & $0.264(40)$ & $1.54(15)$ & $4.00(13)$ \\
\hline BJJB 130 & -1.5 & 24.0 & $\sim 100$ & 2200 & $0.000(28)$ & $0.425(41)$ & $0.508(96)$ & $0.079(68)$ & $2.18(25)$ & $4.00(13)$ \\
\hline BJJB 134 & -1 & 24.0 & $\sim 100$ & 2100 & $0.058(21)$ & $0.608(34)$ & $0.382(81)$ & $0.000(54)$ & $3.14(20)$ & $4.17(6)$ \\
\hline BJJB 184 & -1.5 & 12.0 & $\sim 100$ & 2000 & $0.036(22)$ & $0.552(34)$ & $0.511(78)$ & $0.000(53)$ & $2.90(20)$ & $4.12(7)$ \\
\hline BJJB 185 & -1.5 & 19.0 & 279.4 & 2100 & $0.000(25)$ & $0.531(42)$ & $0.523(95)$ & $0.021(64)$ & $2.26(24)$ & $4.00(9)$ \\
\hline Mo cow IW 0.5 & 0.5 & 0.0001 & 89.3 & 1300 & $0.627(64)$ & $0.369(112)$ & $0.000(153)$ & $0.014(87)$ & $5.27(61)$ & $5.23(13)$ \\
\hline Mo cow IW & 0 & 0.0001 & 64.7 & 1300 & $0.456(31)$ & $0.477(43)$ & $0.000(93)$ & $0.126(71)$ & $4.62(27)$ & $4.96(6)$ \\
\hline Mo cow IW-0.5 & -0.5 & 0.0001 & 16.5 & 1300 & $0.000(61)$ & $0.712(68)$ & $0.288(30)$ & - & $2.85(45)$ & $4.00(17)$ \\
\hline Mo cow IW -1.5 & -1.5 & 0.0001 & 1.6 & 1300 & $0.000(75)$ & $0.625(85)$ & $0.375(37)$ & - & $2.50(56)$ & $4.00(23)$ \\
\hline Mo cow IW-2.8 & -2.8 & 0.0001 & 19.7 & 1300 & $0.055(9)$ & $0.676(14)$ & $0.269(4)$ & - & $3.03(8)$ & $4.15(2)$ \\
\hline Ank IW+2 & 2 & 0.0001 & 13742 & 1300 & $0.981(95)$ & $0.018(11)$ & $0.000(40)$ & $0.000(34)$ & $5.86(10)$ & $6.00(5)$ \\
\hline Ank IW+1 & 1 & 0.0001 & 6905 & 1300 & $0.963(9)$ & $0.023(13)$ & $0.000(31)$ & $0.000(21)$ & $5.83(8)$ & $5.91(3)$ \\
\hline Ank IW & 0 & 0.0001 & 3160.7 & 1300 & $0.969(30)$ & $0.038(51)$ & $0.001(73)$ & $0.000(43)$ & $5.93(28)$ & $5.88(10)$ \\
\hline Ank IW-1 & -1 & 0.0001 & 4479 & 1300 & $0.623(15)$ & $0.381(20)$ & $0.063(45)$ & $0.000(34)$ & $5.29(13)$ & $5.21(3)$ \\
\hline Ank IW-2 & -2 & 0.0001 & 722.3 & 1300 & $0.172(25)$ & $0.719(35)$ & $0.105(76)$ & $0.054(56)$ & $4.00(22)$ & $4.38(5)$ \\
\hline mo- $1 \dagger$ & 0.5 & 1.0 & n.d. & 1400 & $0.611(13)$ & $0.000(18)$ & $0.154(43)$ & $0.274(30)$ & $3.78(11)$ & $5.96(6)$ \\
\hline mo- $2 \dagger$ & 0.5 & 1.5 & n.d. & 1400 & $0.000(38)$ & $0.441(57)$ & $0.420(133)$ & $0.202(93)$ & $2.16(34)$ & $4.00(17)$ \\
\hline mo- $2 \mathrm{~B}^{\dagger} \dagger$ & 0.5 & 1.5 & n.d. & 1400 & $0.51(19)$ & $0.257(35)$ & $0.152(52)$ & $0.161(30)$ & $3.86(19)$ & $5.25(6)$ \\
\hline mo- $4 \mathrm{~A} \dagger$ & 0.5 & 3.0 & n.d. & 1500 & $0.246(27)$ & $0.000(38)$ & $0.475(83)$ & $0.314(62)$ & $1.91(23)$ & $5.96(30)$ \\
\hline BJJB 187 & 0.5 & 4.0 & n.d. & 1600 & $0.105(16)$ & $0.000(25)$ & $0.453(59)$ & $0.475(40)$ & $1.05(15)$ & $5.96(47)$ \\
\hline
\end{tabular}

Samples from previous studies: $\S$ - Righter and Drake (1999); $\$$ - Righter et al. (2010); $\uparrow-$ Righter et al. (2013); n.d. = not determined $\mathrm{Mo}^{6}, \mathrm{Mo}^{4}$, and $\mathrm{Mo}^{0 \mathrm{a}}$ and $\mathrm{Mo}^{0 \mathrm{~b}}$ are the fraction of each species from the fit, and the "a" and "b" are the two reduced components observed in the spectra (see text for further discussion). 